\title{
Climate sensitivity to carbon dioxide and moist greenhouse threshold of earth-like planets under an increasing solar forcing
}

Article

Accepted Version

Gomez-Leal, I., Kaltenegger, L., Lucarini, V. and Lunkeit, F. (2018) Climate sensitivity to carbon dioxide and moist greenhouse threshold of earth-like planets under an increasing solar forcing. The Astrophysical Journal, 869 (2). 129. ISSN 0004-637X doi: https://doi.org/10.3847/1538-4357/aaea5f Available at https://centaur.reading.ac.uk/80710/

It is advisable to refer to the publisher's version if you intend to cite from the work. See Guidance on citing.

To link to this article DOI: http://dx.doi.org/10.3847/1538-4357/aaea5f

Publisher: Institute of Physics

All outputs in CentAUR are protected by Intellectual Property Rights law, including copyright law. Copyright and IPR is retained by the creators or other copyright holders. Terms and conditions for use of this material are defined in the End User Agreement.

www.reading.ac.uk/centaur 
Central Archive at the University of Reading

Reading's research outputs online 
Draft VERSion November 19, 2018

Typeset using LATEX twocolumn style in AASTeX61

\title{
CLIMATE SENSITIVITY TO CARBON DIOXIDE AND MOIST GREENHOUSE THRESHOLD OF EARTH-LIKE PLANETS UNDER AN INCREASING SOLAR FORCING
}

\author{
Illeana Gómez-Leal,${ }^{1,2}$ Lisa Kaltenegger,${ }^{1,2}$ Valerio Lucarini,${ }^{3,4}$ and Frank Lunkeit ${ }^{4}$
}

\footnotetext{
${ }^{1}$ Carl Sagan Institute, 311 Space Sciences Bldg., Cornell University, Ithaca, NY14853-6801, USA.

${ }^{2}$ Cornell Center for Astrophysics \& Planetary Science, 311 Space Sciences Bldg., Cornell University, Ithaca, NY14853-6801, USA.

${ }^{3}$ Department of Mathematics and Statistics, Whiteknights, PO Box 220, University of Reading, Reading RG6 6AX, UK.

${ }^{4}$ CEN, Institute of Meteorology, University of Hamburg. Grindelberg 5, D-20144 Hamburg. Germany.
}

\section{Submitted to ApJ}

\begin{abstract}
Carbon dioxide is one of the major contributors to the radiative forcing, increasing both the temperature and the humidity of Earth's atmosphere. If the stellar irradiance increases and water becomes abundant in the stratosphere of an Earth-like planet, it will be dissociated and the resultant hydrogen will escape from the atmosphere. This state is called the moist greenhouse threshold (MGT). Using a global climate model (GCM) of intermediate complexity, we explore how to identify this state for different $\mathrm{CO}_{2}$ concentrations and including the radiative effect of atmospheric ozone for the first time. We show that the MGT correlates with the inflection point in the water vapor mixing ratio in the stratosphere and a peak in the climate sensitivity. For $\mathrm{CO}_{2}$ concentrations between 560 and 200 ppm, the MGT is reached at a surface temperature of $320 \mathrm{~K}$. Despite the higher simplicity of our model, our results are consistent with similar simulations without ozone by complex GCMs, suggesting that they are robust indicators of the MGT. We discuss the implications for the inner edge of the habitable zone as well as the water loss timescales for Earth analog planets.
\end{abstract}

Keywords: Earth — planets and satellites: terrestrial planets — planets and satellites: atmospheres — 


\section{INTRODUCTION}

The temperature of our planet depends on the solar luminosity, which will increase by $10 \%$ in the next billion years and by $80 \%$ until the end of the Main Sequence (e.g. Gough 1981; Bahcall et al. 2001; Schröder and Connon Smith 2008). The rising temperatures will increase the evaporation and are expected to cause the loss of the water reserves of our planet (e.g. Kasting et al. 1984; Kasting 1988; Kasting et al. 1993; Kopparapu et al. 2013). Two main scenarios have been proposed for the water loss: a) if the moist greenhouse effect dominates the climate, the water vapor becomes abundant in the stratosphere, it will be dissociated by the solar UV radiation, and the resultant hydrogen will escape gradually from the planet's atmosphere (Towe 1981); b) if the runaway greenhouse effect dominates, the oceans evaporate, leading to a steamy atmosphere. The surface temperature will rise above $1800 \mathrm{~K}$ (Kopparapu et al. 2013) and the water will be rapidly lost.

The moist greenhouse state and the runaway greenhouse state are used to define the inner boundary of the conservative Habitable Zone (e.g. Kasting 1988; Kasting et al. 1993; Kopparapu et al. 2013; Ramirez and Kaltenegger 2014, 2016). The study of the radiative conditions that lead to them is essential to understand the evolution of our planet's climate, as well as the habitability of exoplanets (e.g. Abe et al. 2011; Wordsworth and Pierrehumbert 2013; Yang et al. 2014). The planetary climate changes according to the amount of the solar irradiance. As the temperature rises and the humidity is enhanced, the opacity of the atmosphere increases, limiting the outgoing longwave radiation (OLR) of the planet. The OLR is maximum at the Simpson-Nakajima limit (Simpson 1927; Nakajima et al. 1992; Goldblatt et al. 2013), when the lower atmosphere becomes opaque to the thermal radiation due to the abundance of water vapor. Thus, at this stage, an increase in the solar irradiance does not produce an increase in the emission, but a large global warming, raising the temperatures further.

One-dimensional simulations predict that the Earth will enter a moist greenhouse state when the total solar irradiance (TSI) will be 1.015 times greater than the present solar constant $\left(\mathrm{S}_{0}=1361.27 \mathrm{~W} \cdot \mathrm{m}^{-2}\right)$ (Kopparapu et al. 2013). This places the moist greenhouse limit at an orbital distance of $0.99 \mathrm{AU}$ in our solar system, very close to Earth's orbit. These same simulations predict that the runaway greenhouse will dominate when the $\mathrm{TSI}=1.06 \mathrm{~S}_{0}$, which corresponds to 0.97 AU. However, these models do not self-consistently simulate the changes in the surface albedo, the distribution of the humidity and the clouds, the variation in the circulation of the atmosphere, and in general many positive and negative feedback effcts that play an important role in the climate of the planet. Global climate models (GCMs) consider these factors, but the simulation of the hydrological cycle and the clouds is far from a trivial task, especially in exotic conditions. Recent 3D studies have shown discrepancies in the concentration of water vapor, the cloud cover, and the evolution of the planetary albedo with an increasing solar radiation (Leconte et al. 2013; Wolf \& Toon 2015). These studies use 1D standards to identify the moist greenhouse threshold (MGT) in their data: a saturated troposphere and a water vapor mixing ratio of $\mathrm{q}_{r} \sim 3 \mathrm{~g} \cdot \mathrm{kg}^{-1}$ (Kasting et al. 1993). Leconte et al. (2013), using the Laboratoire de Météorologie Dynamique de Paris LMD Generic GCM (LMDG), did not find a moist greenhouse state, but a runaway state since the troposphere remains unsaturated and the water vapor mixing ratio has a lower value than $1 \mathrm{D}$ models. Wolf \& Toon (2015), using the Community Atmosphere Model version 4 (CAM4), found two possible moist greenhouse states: one at $\mathrm{TSI}=1.125 \mathrm{~S}_{0}$ and $\mathrm{q}_{r} \sim 1.5 \cdot 10^{-5} \mathrm{~g} \cdot \mathrm{kg}^{-1}$, correlating with an abrupt increase in the climate sensitivity; the other, at TSI $=1.190 \mathrm{~S}_{0}$, is identified following the 1D standard value of $\mathrm{q}_{r} \sim 3 \mathrm{~g} \cdot \mathrm{kg}^{-1}$. Both models show that the troposphere is unsaturated at these states, contrary to 1D models predictions. More recently, Kasting et al. (2015) has obtained a water vapor mixing ratio of $\sim 10^{-6} \mathrm{~g} \cdot \mathrm{kg}^{-1}$ at the MGT, using an improved 1D radiative transfer.

These studies show that the value of the water mixing ratio in the stratosphere depends heavily on the model used. In addition, these models do not include ozone, therefore the temperature and humidity of the atmosphere at the present solar irradiance differ from those on Earth.

Carbon dioxide contributes to $60 \%$ of the global radiative forcing of Earth's atmosphere (e.g. Hartmann et al. 2013), raising the temperature and enhancing the hydrologic cycle (Manabe and Wetherald 1975). The radiation forcing due to a variation in the $\mathrm{CO}_{2}$ concentration between a reference state $\left[\mathrm{CO}_{2}\right]^{r}$ and the state of interest $\left[\mathrm{CO}_{2}\right]^{x}$ follows the logarithmic dependence

$$
\Delta F_{x, r}=5.35 \ln \left(\frac{\left[C O_{2}\right]^{x}}{\left[C O_{2}\right]^{r}}\right)
$$

where $\Delta F_{x, r}$ is in $\mathrm{W} / \mathrm{m}^{2}$ (e.g. Arrhenius 1896; Myhre et al. 1998). According to this relation, a doubling of the $\mathrm{CO}_{2}$ concentration is estimated to produce a radiative forcing of $3.7 \mathrm{~W} \cdot \mathrm{m}^{-2}$ by the Intergovernmental Panel on Climate Change (IPCC) assessments (Collins et al. 2013), as well as by radiative transfer models (e.g. Etminan et al. 2016), and by GCMs (Myhre et al. 2013). The solar irradiance required for the transition from a snowball state to a warm state of an Earth-like planet decreases with increasing atmospheric $\mathrm{CO}_{2}$ (Boschi et al. 2013). Therefore, the atmospheric $\mathrm{CO}_{2}$ concentration has an 
influence in planetary habitability.

The greenhouse effect of ozone is also important. Ozone absorbs most of the solar UV radiation through photodissociation, warming the stratosphere. This produces a temperature inversion that determines the level of the tropopause, and increases the temperature and the humidity of the lower atmosphere, as well as the surface temperature. In the last decades, ozone has contributed to the radiative forcing with about $0.35 \mathrm{~W} / \mathrm{m}^{2}$, due to its increase in the troposphere by human activities (Forster et al. 2007), and about $-0.05 \mathrm{~W} / \mathrm{m}^{2}$, due to its decrease in the stratosphere, which is equivalent to $20 \%$ of the $\mathrm{CO}_{2}$ contribution. Including atmospheric ozone is essential to describe Earth's current climate. In the absence of ozone, the temperature inversion in the stratosphere does not occur, UV radiation penetrates deeply in the atmosphere, the water dissociation rates increase, and the temperature gradient extends to higher levels.

The amount of water vapor is enhanced at higher temperatures, having both chemical and radiative effects on the atmosphere. The products of the dissociation of water such as $\mathrm{HO}_{x}$ radicals increase, depleting ozone. However, they also increase $\mathrm{HNO}_{3}$ and remove $\mathrm{NO}_{2}$, slowing ozone depletion. In addition, water vapor absorbs latent heat, cooling the environment and decreasing the reaction rates. Several studies have shown that the radiative effect dominates and increasing water vapor in the atmosphere only depletes ozone in the tropical lower stratosphere and the high latitudes of the southern hemisphere, while elsewhere ozone increases (e.g. Evans et al. 1998; Tian et al. 2009). This indicates that the radiative effect of ozone is enhanced in a warmer atmosphere. However, the interaction between water and ozone is complex to simulate and it has not been studied at high solar irradiances with 3D models.

We use the intermediate complexity model Planet Simulator (PlaSim) to explore the climate sensitivity of an Earth-like planet, including $\mathrm{O}_{3}$ and different $\mathrm{CO}_{2}$ concentrations, as a function of the solar irradiance, in order to constrain the characteristics of the MGT and to derive a new reference quantity for this state. This article is organized as follows: In Section 2, we describe the model and the methods. In Section 3, we present our results. First, we validate our model for the present solar irradiance $\left(\mathrm{S}_{0}=1361.27 \mathrm{~W} \cdot \mathrm{m}^{-2}\right)$, by simulating Earth's climate with the present $\mathrm{O}_{3}$ concentration and $388 \mathrm{ppm}$ of $\mathrm{CO}_{2}$, and we compare our results with atmospheric reanalysis data and previous studies using satellite observations. We test the response of our model to solar forcing by doubling the $\mathrm{CO}_{2}$ pre-industrial concentration (560 ppm) and we compare it to established values. Then, we study the contribution of carbon dioxide to the greenhouse effect, simulating the present Earth with four different $\mathrm{CO}_{2}$ concentrations: $388 \mathrm{ppm}$ (taken as representative of present conditions), $280 \mathrm{ppm}$ (a pre-industrial level), 200 ppm (a typical value during Earth glaciations), and 560 ppm (the double of the pre-industrial concentration). We increase the solar irradiance in subsequent simulations until the atmosphere becomes entirely opaque. As a first approach, we include $\mathrm{O}_{3}$ in a concentration equal to the present values. We study the variation of the surface temperature, the surface albedo, the cloud radiative effect (CRE), the Bond albedo, the water vapor mixing ratio, the stratospheric temperature, and the emissivity of the atmosphere. Finally, we estimate the MGT and the water lifetime of an Earth analog and we compare our results to previous GCM studies. In Section 4, we discuss the results and we present our conclusions in Section 5 .

\section{MODEL AND METHODS}

We have used the intermediate complexity model PlaSim (Fraedrich et al. 2005a,b; Lunkeit et al. 2011) ${ }^{1}$ to simulate the global warming of the Earth under an increasing solar irradiance for several $\mathrm{CO}_{2}$ concentrations. While being simpler than the state-of-the-art GCMs in terms of resolution and adopted parameterizations, intermediate complexity models represent a compromise between sophistication and computation time. PlaSim can simulate a large variety of scenarios and allows us to examine aspects of the climate in a very efficient manner, performing a large number of simulations in a short time. As a result, the model has been instrumental in studying climate change using rigorous methods of statistical mechanics (Ragone et al. 2016). It has the advantage of a great degree of flexibility and robustness when terrestrial, astronomical, and astrophysical parameters are altered. It has been extensively used for studying climate sensitivity to the variation of solar radiation (Lucarini et al. 2010a,b, 2013), $\mathrm{CO}_{2}$ concentration (Boschi et al. 2013), obliquity (Kilic et al. 2017), eccentricity (Linsenmeier et al. 2015), and ozone (Bordi et al. 2012).

The primitive equations for vorticity, divergence, temperature, and surface pressure are solved via the spectral transform method (Eliasen et al. 1970; Orszag 1970). The parameterization in the shortwave radiation (SW) follows Lacis and Hansen (1974) for the cloud-free atmosphere. Transmissivities and albedos for high, middle, and low level clouds are parameterized following Stephens (1978) and Stephens et al. (1984). The downward radiation flux density $F^{\downarrow S W}$ is the product of different transmission

\footnotetext{
1 freely available at https://www.mi.uni-hamburg.de/en/ arbeitsgruppen/theoretische-meteorologie/modelle/plasim. html
} 
factors with the solar flux density $\left(\mathcal{E}_{0}\right)$ and the cosine of the solar zenith angle $\left(\mu_{0}\right)$ as

$$
F^{\downarrow S W}=\mu_{0} \mathcal{E}_{0} \cdot \mathcal{T}_{R} \cdot \mathcal{T}_{H_{2} O} \cdot \mathcal{T}_{O_{3}} \cdot \mathcal{T}_{C} \cdot \mathcal{R}_{S}
$$

which includes the transmissivities due to Rayleigh scattering $(R)$, cloud droplets $(C)$, water and ozone absorption (Chappuis band), and $R_{S}$ comprises different surface albedo values. $\mathcal{E}_{0}$ and $\mu_{0}$ are computed following Berger (1978a,b). For the clear-sky longwave (LW) radiation, the broadband emissivity method is employed (Manabe \& Möller 1961; Rodgers 1967; Sasamori 1968; Katayama 1972; Boer et al. 1984).

$$
\begin{gathered}
F^{\uparrow L W}(z)=\mathcal{A}_{S} B\left(T_{S}\right) \mathcal{T}_{(z, 0)}+\int_{0}^{z} B\left(T^{\prime}\right) \frac{\delta \mathcal{T}_{\left(z, z^{\prime}\right)}}{\delta z^{\prime}} \\
F^{\downarrow L W}(z)=\int_{\infty}^{z} B\left(T^{\prime}\right) \frac{\delta \mathcal{T}_{\left(z, z^{\prime}\right)}}{\delta z^{\prime}}
\end{gathered}
$$

where $B(T)$ denotes the blackbody flux and $\mathcal{A}_{\mathcal{S}}$ is the surface emissivity. The transmissivities for water vapor, carbon dioxide, and ozone are taken from Sasamori (1968). These empirical formulas are obtained from meteorological data and are dependent on the effective amount of each gas. The effective amount is obtained as

$$
u_{X}\left(p, p^{\prime}\right)=\frac{1}{g} \int_{p}^{p^{\prime}} q_{X}\left(\frac{p^{\prime \prime}}{p_{0}}\right) d p^{\prime \prime}
$$

where $g$ is the gravitational acceleration, $q_{X}$ is the mixing ratio, $p$ is the pressure, and $p_{0}=1000 \mathrm{hPa}$ is the reference pressure.

The $\mathrm{H}_{2} \mathrm{O}$ continuum absorption is parameterized by

$$
\tau_{\text {cont }}^{\mathrm{H}_{2} \mathrm{O}}=1 .-\exp \left(-0.03 u_{\mathrm{H}_{2} \mathrm{O}}\right)
$$

To account for the overlap between the water vapor and the carbon dioxide bands near $15 \mu \mathrm{m}$, the $\mathrm{CO}_{2}$ absorption is corrected by a $\mathrm{H}_{2} \mathrm{O}$ transmission at $15 \mu \mathrm{m}$ given by

$$
\mathcal{T}_{\mathrm{H}_{2} \mathrm{O}}^{15 \mu m}=1.33-0.832\left(u_{\mathrm{H}_{2} \mathrm{O}}+0.0286\right)^{0.26}
$$

Cloud flux emissivities are obtained from the cloud liquid water content (Stephens et al. 1984) by

$$
\mathcal{A}^{c l}=1 .-\exp \left(-\beta_{d} k^{c l} W_{L}\right)
$$

where $\beta_{d}=1.66$ is the diffusivity factor, $k^{c l}$ is the mass absorption coefficient, set to a default value of $0.1 \mathrm{~m}^{2} / \mathrm{g}$ (Slingo and Slingo 1991), and $W_{L}$ is the cloud liquid water path. For a single layer between z and z' with the fractional cloud cover $C$, the total transmissivity is

$$
\mathcal{T}_{\left(z, z^{\prime}\right)}^{*}=\mathcal{T}_{\left(z, z^{\prime}\right)}\left(1 .-C \mathcal{A}^{c l}\right)
$$

where $\mathcal{T}_{\left(z, z^{\prime}\right)}$ is the clear sky transmissivity. Random overlapping of clouds is assumed for multilayers and the total transmissivity becomes

$$
\mathcal{T}_{\left(z, z^{\prime}\right)}^{*}=\mathcal{T}_{\left(z, z^{\prime}\right)} \Pi_{j}\left(1 .-C_{j} \mathcal{A}_{j}^{c l}\right)
$$

where $j$ denotes each cloud layer.

It includes dry convection, large-scale precipitation, boundary-layer fluxes of latent and sensible heat, and vertical and horizontal diffusion (Louis 1979; Laursen and Eliasen 1989; Roeckner et al. 1992). Penetrative cumulus convection is simulated by a moist convergence scheme (Kuo 1965, 1974) including some improvements: cumulus clouds are assumed to exist only if the environmental air temperature and moisture are unstable stratified with respect to the rising cloud parcel, and the net ascension is positive. Shallow convection is represented following Tiedtke (1988) and clouds originated by extratropical fronts are simulated considering the moisture contribution between the lifting level and the top of the cloud, instead of the total column. The effects of water, carbon dioxide, and ozone are taken into account in the radiative transfer. However, the interaction between water and ozone depends strongly on temperature and on their distributions over the planet, it is complex to simulate in GCMs, therefore the evolution of the ozone concentration with an increasing solar irradiance is not yet well understood (Evans et al. 1998; Tian et al. 2009). As a first approach, we use the present distribution of ozone in all our simulations, in order to take in account its radiative effect as a function of the solar irradiance. The ozone concentration is prescribed following the distribution described by Green (1964),

$$
u_{O_{3}}(z)=\left(\alpha+\alpha e^{-\beta / c}\right) /\left(1+e^{(z-\beta) / c}\right)
$$

where $u_{O_{3}}(z)$ is the ozone concentration in a vertical column above the altitude $z, \alpha$ is the total ozone in the vertical column above the ground, $\beta$ is the altitude where the ozone concentration is maximal, and $c$ is a fitting parameter. Equation 11 fits closely the mid-latitude winter ozone distribution with $\alpha=0.4 \mathrm{~cm}, \beta=20 \mathrm{~km}$, and $c=5 \mathrm{~km}$. The latitudinal variation and the annual cycle are modeled by,

$\alpha(t, \phi)=a_{0}+a_{1} \cdot \sin (\phi)+a_{c} \cdot \sin (\phi) \cdot \cos \left(2 \pi\left(d-d_{o f f}\right) / n\right)$

where $t$ is time, $\phi$ is latitude, $d$ is the day of the year, $\mathrm{d}_{\text {off }}$ an offset, $n$ the number of days per year, $a_{0}=0.25, a_{1}=0.11$, and $a_{c}=0.08$. This representation of the ozone concentration is simple, but it allows studying the sensitivity of the problem. The global atmospheric energy balance is improved by re-feeding the kinetic energy losses due to surface friction and horizontal and 
vertical momentum diffusion (Lucarini et al. 2010b). A diagnostic of the entropy budget is available (Fraedrich and Lunkeit 2008). The average energy bias on the energy budget is smaller than $0.5 \mathrm{~W} \cdot \mathrm{m}^{-2}$ in all simulations, which it is achieved locally by an instantaneous heating of the air (Lucarini and Ragone 2011).

We use a T21 horizontal resolution $\left(5.6^{\circ} \times 5.6^{\circ}\right.$ on a gaussian grid) and 18 vertical levels with the uppermost level at $40 \mathrm{hPa}$. This resolution enables an accurate representation of the large-scale circulation features and the global thermodynamical properties of the planet (Pascale et al. 2011). The land surface scheme has five diffusive layers for the temperature and a bucket model for the soil hydrology. Our simulations include a $50 \mathrm{~m}$ mixed-layer ocean and a thermodynamic sea-ice model. Glaciers (prescribed as regions of permanent ice and snow) are omitted, since they produce problems in the energy budget at high surface temperatures. We calculate the surface energy budget as

$$
\Delta E=F_{S W}^{n e t}-F_{L W}^{n e t}-F_{L H}^{n e t}-F_{S H}^{n e t}-\rho_{w} L_{f} v_{S M}
$$

where $F_{S W}^{n e t}$ is the net SW radiative flux, $F_{L W}^{n e t}$ is the net $L W$ radiative flux, $F_{L H}^{n e t}$ is the latent heat flux, $F_{S H}^{n e t}$ is the sensible heat flux, $\rho_{w}$ is the density of water, $L_{f}$ is the latent heat of fusion, and $v_{S M}$ is the snow melt. We obtain a consistent energy budget $<0.02 \mathrm{~W} \cdot \mathrm{m}^{-2}$. We have studied the evolution of the climate increasing the solar irradiance for five values of $\mathrm{CO}_{2}$ atmospheric concentration: $388 \mathrm{ppm}$ (present value), $280 \mathrm{ppm}$ (a pre-industrial level), $200 \mathrm{ppm}$ (a typical value during Earth glaciations), and $560 \mathrm{ppm}$ (double of the preindustrial level). We increase the solar irradiance from the present solar irradiance $\left(1361.27 \mathrm{~W} \cdot \mathrm{m}^{-2}\right)$ until the efficient emissivity of the atmosphere (see Section 2.1) is near unity. Each simulation has a length of 100 years to ensure that the system achieves the equilibrium well before the end of the run and the statistical results are averaged over the last 30 years in order to rule out the presence of transient effects.

The TSI and the concentrations of $\mathrm{CO}_{2}$ and $\mathrm{O}_{3}$ are inputs in the model. The surface temperature $\left(\mathrm{T}_{S}\right)$ is calculated as the global mean of the near surface air temperature. The effective temperature is calculated as the global mean of the radiative temperature at the top-of-the-atmosphere (TOA), $T_{\text {eff }}=\left(F_{L W}^{T O A} / \sigma\right)^{1 / 4}$, where $\mathrm{F}_{L W}^{T O A}$ is the OLR at TOA and $\sigma$ is the StefanBoltzmann constant. The Bond albedo is calculated as $A=1-\left(4 \cdot F_{S W}^{T O A} / S_{0}\right)$, where $\mathrm{F}_{S W}^{T O A}$ is the reflected radiation at TOA and $\mathrm{S}_{0}$ is the solar constant. The normalized greenhouse parameter is calculated as $g_{n}=1-\left(T_{e f f} / T_{S}\right)^{4}$. The CRE is calculated as the difference between the upward flux for clear-sky and for all-sky conditions $C R E=F_{\text {clear-sky }}^{u p}-F_{\text {all-sky }}^{u p}$ for both SW and LW ranges. The global mean temperature $\left(\mathrm{T}_{40}\right)$ and the water vapor mixing ratio $\left(q_{r}\right)$ in the stratosphere are calculated at $40 \mathrm{hPa}$. This level corresponds to an altitude about $25 \mathrm{~km}$ on the present Earth and it represents a compromise between the concentration and the dissociation of $\mathrm{O}_{2}, \mathrm{H}_{2} \mathrm{O}$, and $\mathrm{O}_{3}$ (e.g. Garcia \& Solomon 1983; Fioletov 2008). The standard deviation is at least one order of magnitude lower than the values of the results presented in Tables 3 and 4, thus, the errorbars in the figures are too small to be seen.

Water is a trace gas (volumetric concentration $\chi \leq 1 \%$ ) in the present atmosphere, but at higher temperatures it may become dominant, having an impact on the variation of the atmospheric mass and pressure (non-diluted regime). We calculate the water mixing ratio corresponding to $\chi=1 \%$ as $q_{t}=m_{w} / m_{a}=\chi\left(M_{w} / M_{a}\right)=$ $6.3 \mathrm{~g} \cdot \mathrm{kg}^{-1}$, where $m_{w}$ and $m_{a}$ represent the masses of water and air, respectively, and $M_{w}$ and $M_{a}$ are the molar masses. At the MGT, $q_{r} \sim 7.5 \mathrm{~g} \cdot \mathrm{kg}^{-1}$ at $40 \mathrm{hPa}$ (see Section 3), which corresponds to $\chi=1.1 \%$. Since $q_{r} \sim q_{t}$, water vapor is not dominant in the atmosphere and we do not implement the non-diluted regime of water in the model.

\subsection{The Moist Greenhouse Threshold}

Kasting et al. (1993) defined the MGT as the state at which the water vapor mixing ratio in the stratosphere increases considerably with the solar forcing, obtaining a value of $3 \mathrm{~g} \cdot \mathrm{kg}^{-1}$ using a radiative convective model. This value has been used by GCM studies to identify the MGT (e.g. Leconte et al. 2013; Wolf \& Toon 2015).

Instead of using the value calculated by $1 \mathrm{D}$ models, we calculate the curve of the water vapor mixing ratio at $40 \mathrm{hPa}$ as a function of solar irradiance using a polynomial approximation for each $\mathrm{CO}_{2}$ concentration series. We identify the MGT with the inflection point of the curve, which corresponds to the maximum increase of $q_{r}$ with solar irradiance, as $\left(\mathrm{q}_{r}^{d}, S_{M G T}\right)$, where $q_{r}^{d}$ is the value of the water mixing ratio and $S_{M G T}$ is the TSI at that point. We derive the equivalent orbital distance (D) of $S_{M G T}$ in the present solar system as $D=\left(S_{0} / S_{M G T}\right)^{1 / 2}$, where $D$ is expressed in astronomical units ( $\mathrm{AU}$ ) and $S_{M G T}$ is a multiple of the present solar constant $\left(S_{0}=1361.27 \mathrm{~W} \cdot \mathrm{m}^{-2}\right)$.

Taking into account the bulk effect of the atmosphere, the radiative balance of the planet can be expressed as

$$
\frac{S}{4}(1-A)=\frac{2-\epsilon}{2} \sigma T_{S}^{4}
$$




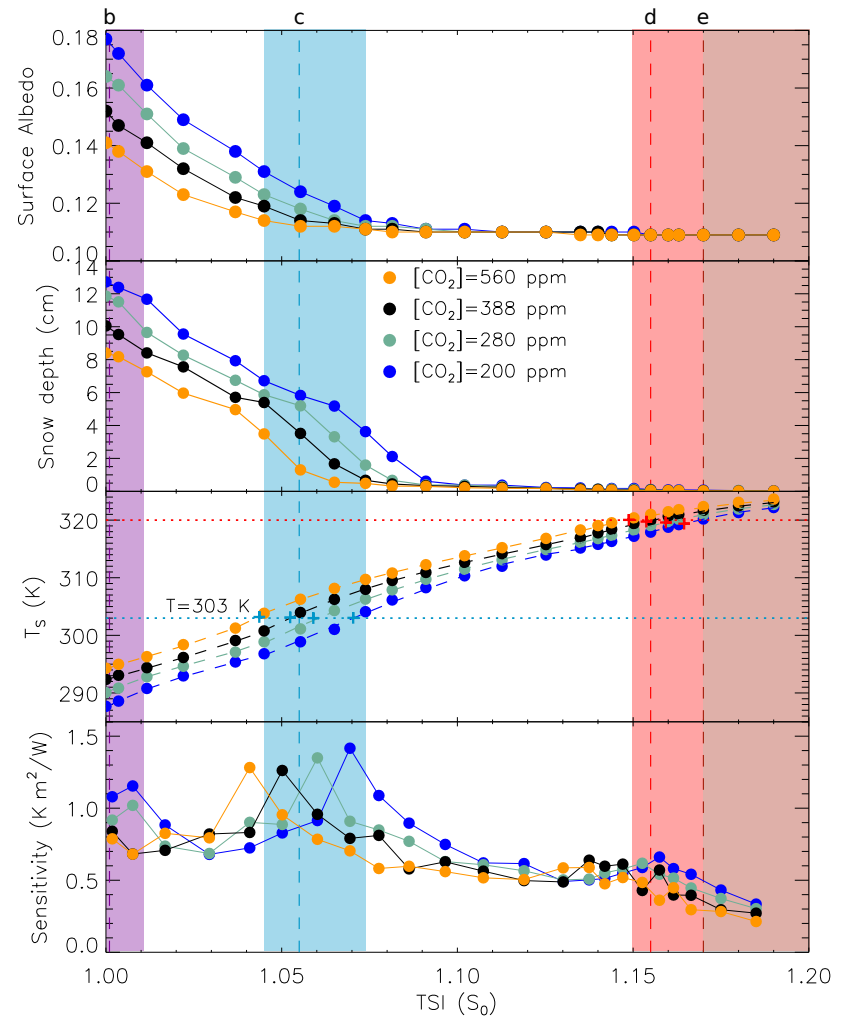

Figure 1. Surface albedo, snow depth, surface temperature, and climate sensitivity as a function of the total solar irradiance (TSI, in units of the solar constant, $S_{0}$ ) for four $\mathrm{CO}_{2}$ concentrations. The dashed lines indicate the states at the maximum cloud fraction (b), the complete melt of the polar ice caps (c), the moist greenhouse initiation (d), and the state where the atmosphere becomes opaque (e) for a $\left[\mathrm{CO}_{2}\right]=388 \mathrm{ppm}$. The stripes indicate the same state from a $\left[\mathrm{CO}_{2}\right]=560 \mathrm{ppm}$ (left limit) to a $\left[\mathrm{CO}_{2}\right]=200 \mathrm{ppm}$ (right limit). The crosses correspond to the inflection points of the polynomial fittings (dashed curves) of the surface temperature series of each case (Table 3).

where $S$ is the solar irradiance, $A$ is the Bond albedo of the planet, $\epsilon$ is the efficient emissivity of the atmosphere, $\sigma$ is the Stefan-Boltzman constant, and $T_{S}$ is the surface temperature. Then, the efficient emissivity of the atmosphere can be calculated as

$$
\epsilon=2 \cdot\left(1-\left(F_{T O A} / F_{S}\right)\right)
$$

where $F_{T O A}$ and $F_{S}$ are the outgoing LW fluxes at the top of the atmosphere and at the surface, respectively. Relevant changes on the planetary climate are identified by the analysis of the climate sensitivity $(\zeta)$,

$$
\zeta=\frac{\Delta T_{S}}{(1-A)(\Delta S / 4)}
$$

where $\Delta T_{S}$ is the change in the global surface temperature, $A$ is the Bond albedo, and $\Delta S$ is the change in solar irradiance. In order to obtain a better accuracy on the point where these changes occur, we perform a

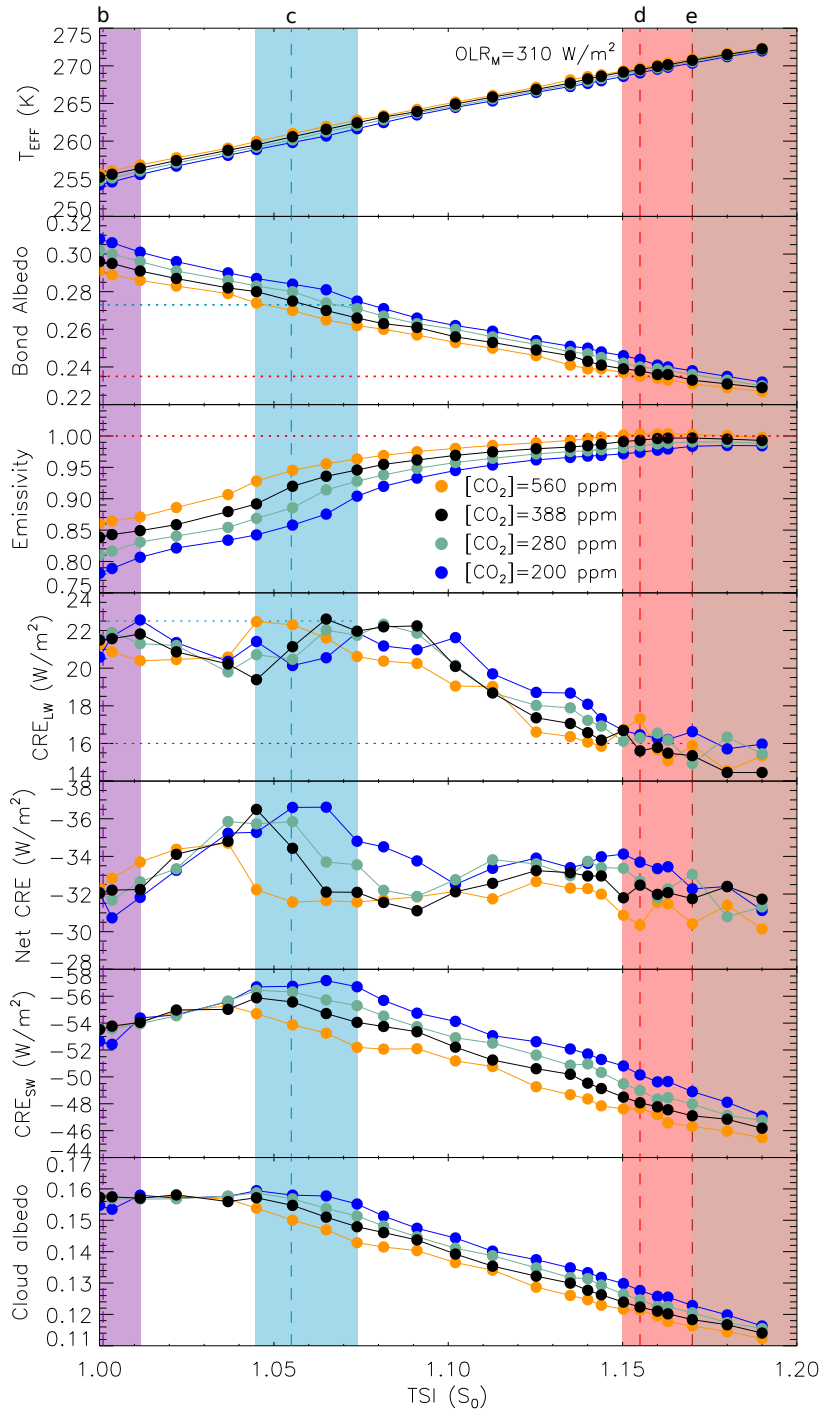

Figure 2. Effective temperature, Bond albedo, emissivity, cloud radiative effect (CRE) for the longwave (LW) radiation, net CRE, CRE for the shortwave (SW) radiation, and cloud albedo as a function of the total solar irradiance (TSI) for four $\mathrm{CO}_{2}$ concentrations. The dashed lines indicate the states at the maximum cloud fraction (b), the complete melt of the polar ice caps (c), the moist greenhouse initiation (d), and the state where the atmosphere becomes opaque (e) for a $\left[\mathrm{CO}_{2}\right]=388 \mathrm{ppm}$. The stripes indicate the same state from a $\left[\mathrm{CO}_{2}\right]=560 \mathrm{ppm}$ (left limit) to a $\left[\mathrm{CO}_{2}\right]=200 \mathrm{ppm}$ (right limit). The maximum outgoing longwave radiation (OLR) shown in our simulations is $310 \mathrm{~W} \cdot \mathrm{m}^{-2}$.

polynomial approximation of the variable series and we derive the inflection point (see Section 3).

\subsection{The water loss}

In a moist greenhouse state, the water loss is limited by the rate of mass transport to the homopause. Here, we have addressed the simplified problem where water dissociates completely into hydrogen, and despite possible reactions with methane in the stratosphere, the water 


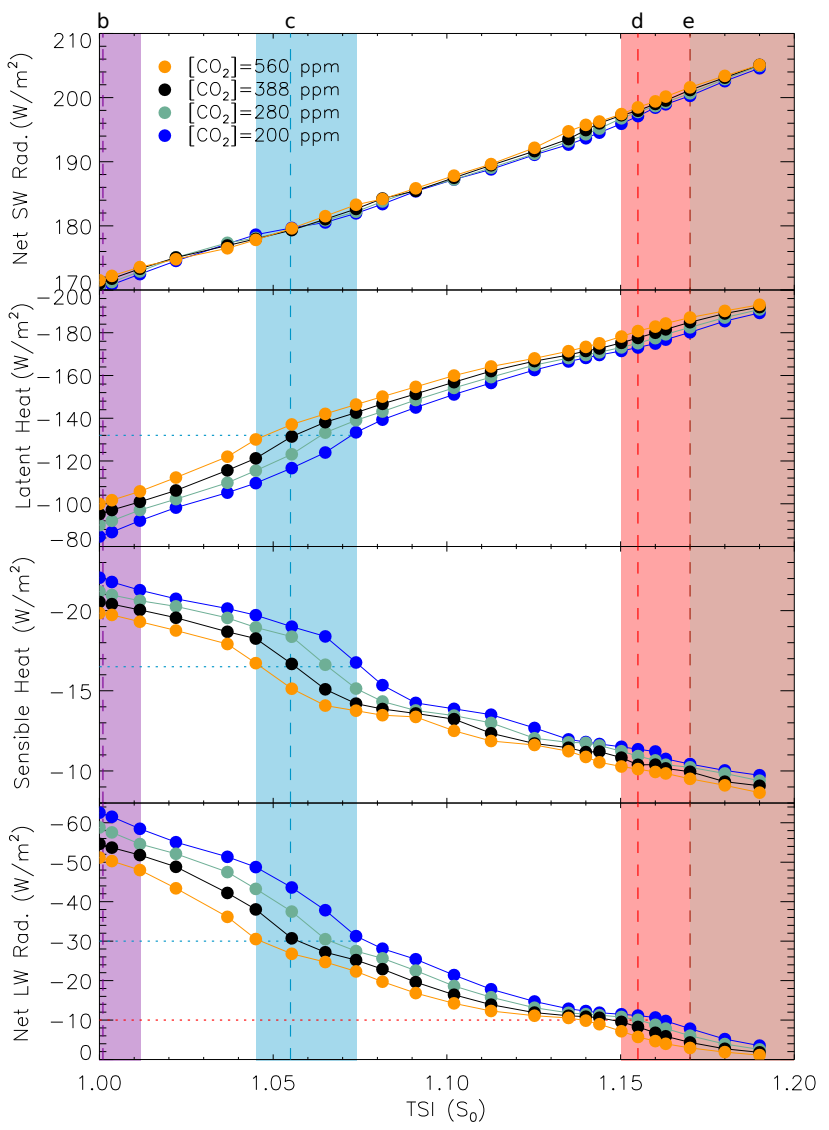

Figure 3. Net shortwave radiation, latent heat flux, sensible heat flux, and net longwave radiation (all in $\mathrm{W} \cdot \mathrm{m}^{-2}$ ) as a function of the total solar irradiance (in units of the solar constant, $S_{0}$ ) for four $\mathrm{CO}_{2}$ concentrations. Negative values correspond to upward flux. The dashed lines indicate the states at the maximum cloud fraction (b), the complete melt of the polar ice caps (c), the moist greenhouse initiation (d), and the state where the atmosphere becomes opaque (e) for a $\left[\mathrm{CO}_{2}\right]=388 \mathrm{ppm}$. The stripes indicate the same state from a $\left[\mathrm{CO}_{2}\right]=560 \mathrm{ppm}$ (left limit) to a $\left[\mathrm{CO}_{2}\right]=200 \mathrm{ppm}$ (right limit). The horizontal dotted lines indicate a similar value at the same state.

vapor concentration at the homopause can be approximated to the water vapor concentration at the stratosphere (Hunten 1973; Kasting et al. 1993; Wolf \& Toon 2015). These calculations represent a lower limit, since water has to be pumped first into the stratosphere. We estimate the water loss using the diffusion-limited escape rate of atomic hydrogen, which can be approximated as

$$
\Phi_{H} \simeq\left(b / H_{a}\right) \cdot q_{H}
$$

where $b$ is the average binary diffusion coefficient of hydrogen, $H_{a}$ is the scale height, $\left(b / H_{a}\right)=2.5 \cdot 10^{13} \mathrm{~cm}^{-2}$. $s^{-1}$, and $q_{H}$ is the total mixing ratio of hydrogen at the stratosphere $\left(q_{H} \sim 2 q_{r}\right)$. Taking in account the number of water molecules in the oceans $\left(n=4.416 \cdot 10^{46}\right)$, the total number of hydrogen molecules is $n_{H}=2 \mathrm{n}$, and the lifetime of water $(\tau)$ at a certain state can be calculated

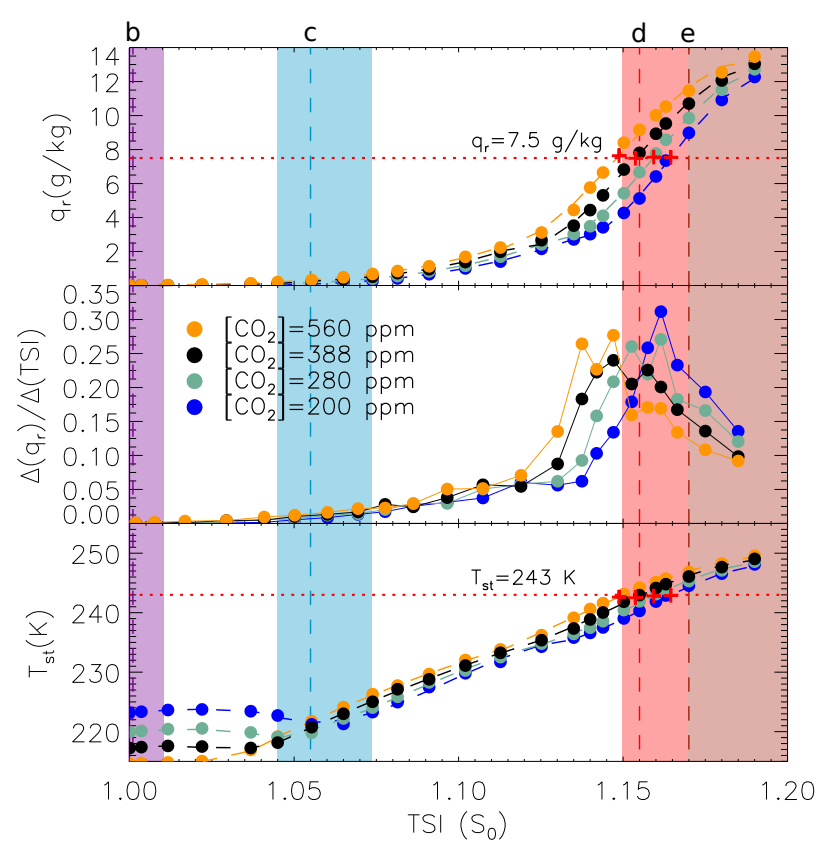

Figure 4. Water vapor mixing ratio $\left(q_{r}\right)$, its variation with the solar forcing (in $\mathrm{g} \cdot \mathrm{kg}^{-1} \cdot \mathrm{W}^{-1} \cdot \mathrm{m}^{2}$ ), and temperature at $40 \mathrm{hPa}$ as a function of the total solar irradiance for four $\mathrm{CO}_{2}$ concentrations. The dashed curves are the polynomial fittings of the $q_{r}$, the crosses indicate their inflection points, and the dotted lines their mean value. The vertical dashed lines indicate the states at the maximum cloud fraction (b), the complete melt of the polar ice caps (c), the moist greenhouse initiation (d), and the state where the atmosphere becomes opaque (e) for a $\left[\mathrm{CO}_{2}\right]=388 \mathrm{ppm}$. The stripes indicate the same state from a $\left[\mathrm{CO}_{2}\right]=560 \mathrm{ppm}$ (left limit) to a $\left[\mathrm{CO}_{2}\right]=200 \mathrm{ppm}$ (right limit).

as

$$
\tau=n_{H} /\left(a \cdot \Phi_{H}\right)
$$

where $a$ is the global area at $40 \mathrm{hPa}$, the reference pressure level previously discussed.

\section{RESULTS}

\subsection{Climate stages}

The effect of increasing solar irradiance is amplified by a positive ice-albedo feedback: as the surface temperature rises, snow melts, decreasing the surface albedo and the Bond albedo (Figs. 1 and 2), and as a result, the planet absorbs more solar radiation. The latent heat transfer from the surface to the atmosphere is enhanced (Fig. 3), the atmosphere becomes more humid and opaque to the thermal radiation, the emissivity and the greenhouse effect increase (Fig. 2), and water vapor becomes abundant in the stratosphere (Fig. 4). An abrupt variation in the climate sensitivity indicates a change in the overall climate of the planet. Previous GCM studies (e.g. Wolf \& Toon 2015; Popp et al. 2016) obtained one climate sensitivity peak corresponding to the moist greenhouse state. Our results show three peaks 


\begin{tabular}{cccc}
\hline$\left[\mathrm{CO}_{2}\right]$ & 1st Peak $\left(\mathrm{S}_{0}\right)$ & 2nd Peak $\left(\mathrm{S}_{0}\right)$ & 3rd Peak $\left(\mathrm{S}_{0}\right)$ \\
\hline 200 & {$[1.004,1.012]$} & {$[1.065,1.074]$} & {$[1.155,1.170]$} \\
280 & {$[1.004,1.012]$} & {$[1.055,1.065]$} & {$[1.150,1.163]$} \\
388 & {$[1.000,1.004]$} & {$[1.045,1.055]$} & {$[1.144,1.155]$} \\
560 & {$[1.000,1.004]$} & {$[1.037,1.045]$} & {$[1.135,1.150]$} \\
\hline
\end{tabular}

Table 1. Climate sensitivity peaks as a function of the solar irradiance (in units of the solar constant $\mathrm{S}_{0}$ ) for different $\mathrm{CO}_{2}$ concentrations (in ppm).

at different values of the solar irradiance, depending on the concentration of carbon dioxide (Fig. 1 and Table 1), indicating important changes in the planet's climate.

Our analysis focus on five climate stages: (a) the climate at the present solar irradiance, (b) the first peak of the climate sensitivity, which correlates with an increase in the cloud albedo, (c) the second peak of the climate sensitivity, which correlates with the complete melt of the planet's ice and snow, (d) the third peak, which we identify with the MGT, and (e) the state when the atmosphere becomes opaque.

(a) Climate under the present solar irradiance - We compare our simulation of the present Earth's climate with the European Centre for Medium-Range Weather Forecasts (ECMWF) climate reanalysis data (ERA), ${ }^{2}$ which provides an accurate representation of the current climate of our planet. Our simulations are at a steady state, contrary to reanalysis data. Nonetheless, since the current climate change is relatively slow, these comparisons are meaningful, identifying any bias of our model with respect to present Earth conditions. We use ERA-20CM flux data (Hersbach et al. 2015) to calculate the global surface temperature, the effective temperature, the Bond albedo of the planet, and the efficient emissivity of the atmosphere for the thermal radiation. The stratospheric temperature and the water mixing ratio have been extracted from ERA-20C data (Poli et al. 2013, 2016).

The surface temperature, the effective temperature, the stratospheric temperature, and the albedo of our present Earth's simulation differ by less than $1 \%$ from ERA data at the same $\mathrm{CO}_{2}$ concentration (388 ppm) and solar irradiance $\left(\mathrm{TSI}=1361.27 \mathrm{~W} \cdot \mathrm{m}^{-2}\right.$, see Table 2 and Fig. 5). The tropopause lies at $200 \mathrm{hPa}$ both in ERA and in our simulations data and the stratospheric temperature is $216 \mathrm{~K}$ and $217 \mathrm{~K}$, respectively. Our data

2 http://www.ecmwf.int/en/research/climate-reanalysis/ browse-reanalysis-datasets

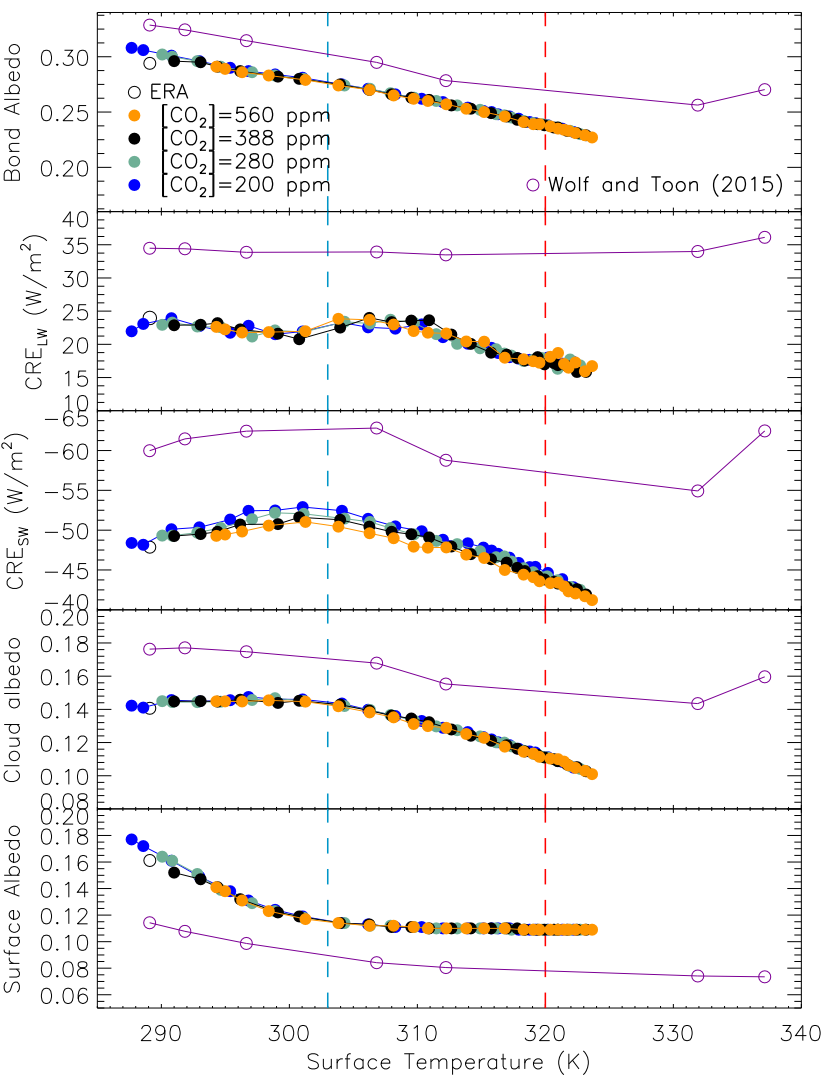

Figure 5. Comparison between the results of this paper, ERA reanalysis data, and Wolf \& Toon (2015). From top to bottom: Bond albedo, longwave cloud radiative effect (CRE), shortwave CRE, cloud albedo, and surface albedo as function of global mean surface temperature. The blue and the red dashed lines correspond to the temperature at the complete ice melt and at the moist greenhouse threshold, respectively, with a $\mathrm{CO}_{2}=388$ ppm.

show a larger water vapor mixing ratio $\left(7.5 \cdot 10^{-3} \mathrm{~g} \cdot \mathrm{kg}^{-1}\right)$ than ERA $\left(2.3 \cdot 10^{-3} \mathrm{~g} \cdot \mathrm{kg}^{-1}\right)$, but the cloud cover and the CRE are well reproduced (Fig. 6). The results for the net solar radiation, latent heat flux, sensible heat flux, and net LW radiation fluxes are in agreement with satellite measurements (Trenberth et al. 2009). The surface temperature for the present $\mathrm{CO}_{2}$ concentration (388 ppm) is about 2 degrees higher than for a preindustrial concentration (280 ppm), in agreement with the IPCC reports (e.g. Hartmann et al. 2013). The surface albedo changes considerably with $\mathrm{CO}_{2}$, showing a $20 \%$ difference between the present and the pre-industrial value (Fig. 1). Larger $\mathrm{CO}_{2}$ concentrations show higher surface temperatures, and enhanced latent heat fluxes and humidity (Fig 6).

We simulate the response to solar forcing by doubling the $\mathrm{CO}_{2}$ concentration $(560 \mathrm{ppm})$ with respect to the pre-industrial level $(280 \mathrm{ppm})$. We obtain an equilibrium climate sensitivity of $2.1 \mathrm{~K}$ and a climate feedback parameter of $1.75 \mathrm{~W} \cdot \mathrm{m}^{-2} \cdot \mathrm{K}^{-1}$, which are within the range of values estimated by the IPCC reports and other 

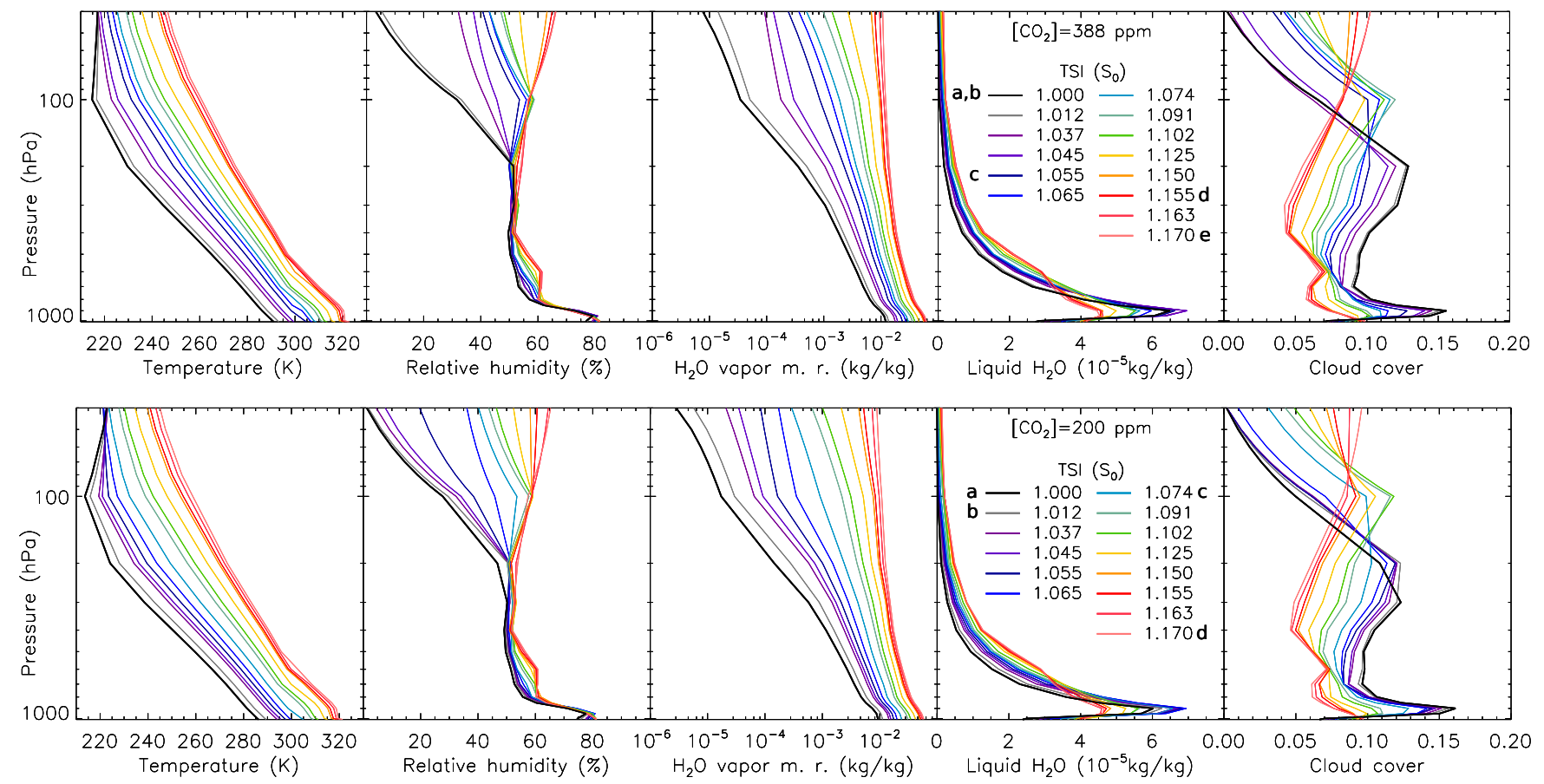

Figure 6. Vertical profiles of surface temperature, relative humidity, water vapor mixing ratio, liquid water content, and cloud cover at several values of the total solar irradiance (TSI, in units of the solar constant $\mathrm{S}_{0}$ ) for two $\mathrm{CO}_{2}$ concentrations. The characters mark the state at the present solar irradiance (a), the state of maximum cloud fraction (b), the state of complete melt of the polar ice caps (c), the state of the moist greenhouse initiation (d), and the state when the atmosphere becomes opaque (e).

recent estimations (e.g. Bindoff et al. 2013; Forster 2016).

(b) Increase in the total cloud fraction - The first peak of climate sensitivity coincides with an increase in the cloud fraction (Figs. 2 and 6), which increases the surface temperature. It occurs between the present solar irradiance and $1.004 \mathrm{~S}_{0}$ for 388 and $560 \mathrm{ppm}$ of $\mathrm{CO}_{2}$, and between 1.004 and $1.012 \mathrm{~S}_{0}$ for 200 and $280 \mathrm{ppm}$ of $\mathrm{CO}_{2}$.

(c) The complete melt of the polar ice caps - The second peak of the climate sensitivity occurs when ice and snow have practically disappeared from the planet's surface (Fig. 1, state c). This happens for similar conditions of temperature, albedo, and relative humidity $(\mathrm{RH})$ for all the $\mathrm{CO}_{2}$ cases tested. As the ice and snow melt, the albedo drops to a minimum value of 0.11 , the surface temperature rises to $303 \mathrm{~K}$, and the $\mathrm{RH}$ increases to $40 \%$ in the stratosphere. With more water in the atmosphere, latent heat flux increases $\left(132 \mathrm{~W} \cdot \mathrm{m}^{-2}\right)$, the temperature difference between the immediate atmosphere and the surface is reduced (Fig. 6), and both the sensible heat flux $\left(16.5 \mathrm{~W} \cdot \mathrm{m}^{-2}\right)$ and the net $\mathrm{LW}$ radiation $\left(\sim 30 \mathrm{~W} \cdot \mathrm{m}^{-2}\right)$ decrease (Fig. 3). The values obtained for these quantities at this state are similar for all the $\mathrm{CO}_{2}$ concentrations tested. Although the RH is enhanced, the higher temperatures rise the dew point and both the low cloud fraction (0.12) and the high cloud fraction (0.10) decrease. High clouds form at an upper level (100 hPa) (Fig. 6). The
Bond albedo and the cloud albedo are reduced by $7 \%$ and by $2 \%$, respectively, and the emissivity of the atmosphere rises to 0.90 . The vertical temperature gradient increases in the tropics, thus the Hadley cells expand, the intensity peak of the subtropical jet streams move to lower pressure levels, and their speed increases (Fig. 7).

Taking advantage of the large number of simulations performed, we calculate the polynomial fitting of the surface temperature series and its inflection point to determine the climate sensitivity change with better precision. The results show an inflection point at $T_{S} \sim 303 \mathrm{~K}$ for all $\mathrm{CO}_{2}$ concentrations tested (Table 3 and Fig. 1).

(d) The MGT - The third climate sensitivity peak correlates with the large increase in humidity at $40 \mathrm{hPa}$, indicating the MGT (Fig. 4, state d). The troposphere is charged with water vapor but it is not completely saturated at this state $(\mathrm{RH} \sim 85 \%$ at the surface and $\mathrm{RH} \sim 65 \%$ in the stratosphere), in agreement with previous 3D studies (Leconte et al. 2013; Wolf \& Toon 2015; Popp et al. 2016). The Hadley cells and the jet streams speed are enhanced with the higher temperatures (Fig. 7). The temperature in the surface boundary layer increases (Fig. 6), due to the infrared water vapor continuum absorption (London 1980). This phenomenon appears as a temperature inversion in previous studies including a water vapor continuum parameterization (Wordsworth and Pierrehumbert 2013; Wolf \& Toon 2015; Popp et al. 2016). The sensible heat flux $\left(11 \mathrm{~W} \cdot \mathrm{m}^{-2}\right)$ and the 

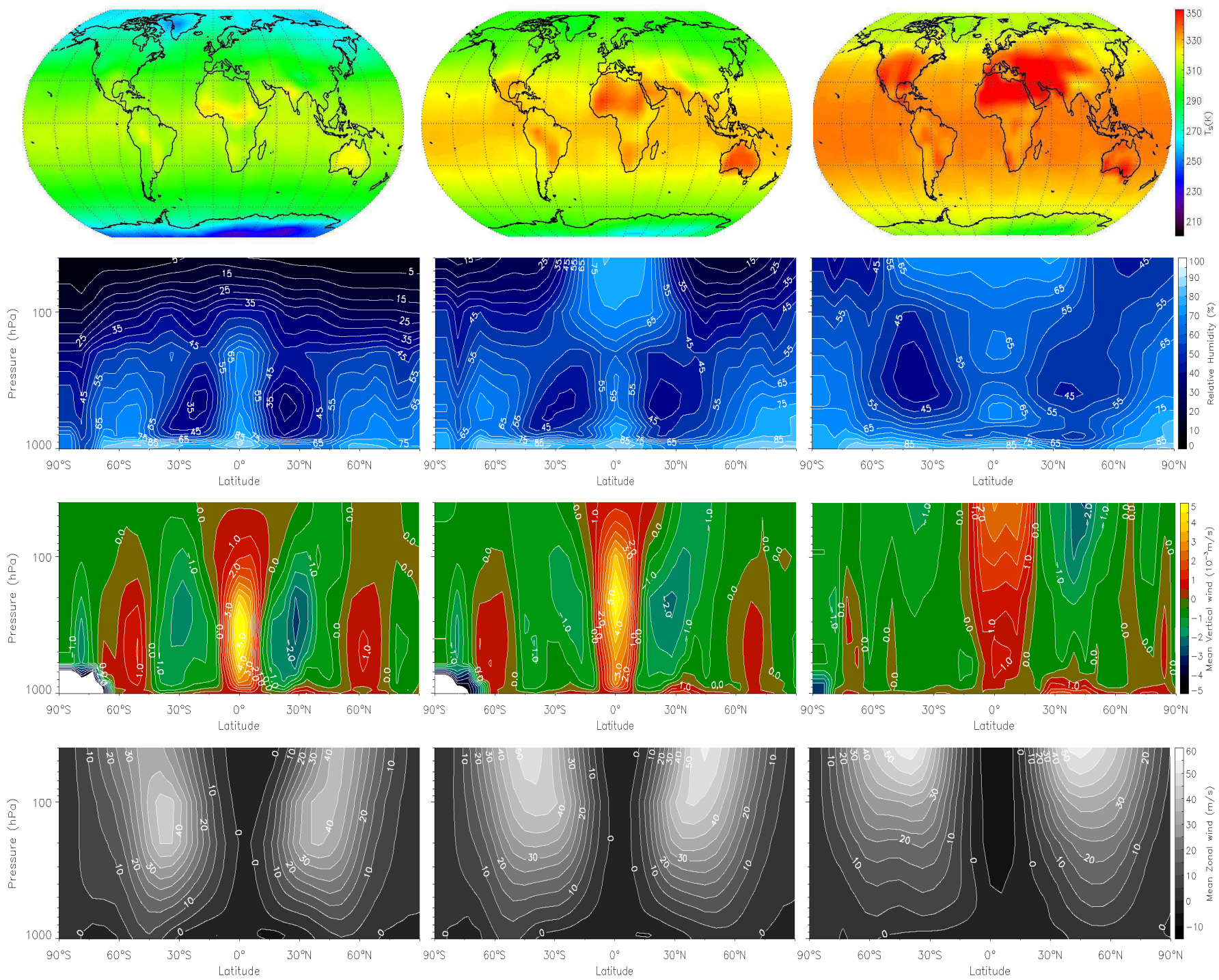

Figure 7. Surface temperature, zonal mean relative humidity, vertical wind, and zonal wind for an atmospheric concentration of $\left[\mathrm{CO}_{2}\right]=388 \mathrm{ppm}$, at the present stellar flux $\left(\mathrm{TSI}=\mathrm{S}_{0}\right.$, left $)$, at the state when the polar ice caps melt completely $(\mathrm{TSI}=1.052 \mathrm{~S}$, middle), and at the moist greenhouse state (TSI $=1.154 \mathrm{~S}_{0}$, right).

net $\mathrm{LW}$ radiation decrease $\left(8 \mathrm{~W} \cdot \mathrm{m}^{-2}\right)$ and the latent heat flux increases $\left(180 \mathrm{~W} \cdot \mathrm{m}^{-2}\right)$. Low and high cloud fractions decrease below $10 \%$ and the emissivity of the atmosphere is enhanced to about 0.99 . The values of these quantities are similar for all the $\mathrm{CO}_{2}$ concentrations tested.

The fitting curve of the water vapor mixing ratio at $40 \mathrm{hPa}$ shows an inflection point (Fig. 4, top chart), indicating the MGT. For $388 \mathrm{ppm}$ of $\mathrm{CO}_{2}$, this occurs at TSI 1.154 $\mathrm{S}_{0}$, which corresponds to an orbital distance of $0.930 \mathrm{AU}$ in the present Solar System. The water vapor mixing ratio at $40 \mathrm{hPa}\left(q_{r} \sim 7.5 \mathrm{~g} \cdot \mathrm{kg}^{-1}\right)$, the stratospheric temperature $\left(\mathrm{T}_{s t} \sim 243 \mathrm{~K}\right)$ and the surface temperature $\left(\mathrm{T}_{S} \sim 320 \mathrm{~K}\right)$ have similar values at this state for all $\mathrm{CO}_{2}$ cases tested (Table 3, Figs. 1 and 4). In order to take the evolution of the luminosity of a solar type star into account, we use the solar data given by Bahcall et al. (2001), which have been calibrated with helioseismology measurements. In the case of a pre-industrial $\mathrm{CO}_{2}$ concentration level (280 ppm), the moist greenhouse becomes dominant at TSI 1.159 $\mathrm{S}_{0}, 50$ million years later than with the present concentration. If the concentration is doubled (560 ppm), the MGT occurs 60 million years earlier than with the present concentration, at TSI 1.149 $\mathrm{S}_{0}$. In an atmosphere with a $\mathrm{CO}_{2}$ concentration similar to that of some Earth glaciations (200 ppm), the MGT is achieved 100 million years later than with the present concentration, at TSI 1.164 $\mathrm{S}_{0}$.

Using the relation between the $\mathrm{CO}_{2}$ concentration and the radiative forcing (Eq. 1), our results can be fitted by 
$\mathrm{CO}_{2}$ AND Habitability on EARTh-Like Planets

\begin{tabular}{|c|c|ccc|cccc|cc|}
\cline { 2 - 10 } \multicolumn{1}{c|}{} & Model & $O_{3}$ & $T S I\left(\mathrm{~W} / \mathrm{m}^{2}\right)$ & {$\left[C O_{2}\right](\mathrm{ppm})$} & $T_{S}(\mathrm{~K})$ & $T_{\text {eff }}(\mathrm{K})$ & $\mathrm{A}$ & $g_{n}$ & $\mathrm{~T}_{40}(\mathrm{~K})$ & $q_{r}(\mathrm{~g} / \mathrm{kg})$ \\
\hline a & ERA & yes & 1361 & 388 & 289.1 & 255.3 & 0.294 & 0.392 & 216 & $2.3 \cdot 10^{-3}$ \\
b & PlaSim & yes & 1361 & 388 & 291.0 & 255.2 & 0.296 & 0.419 & 217 & $7.4 \cdot 10^{-3}$ \\
c & LMDZ $^{i}$ & no & 1365 & 376 & 282.8 & 253.8 & 0.311 & 0.351 & 170 & $1 \cdot 10^{-5}$ \\
d & CAM4 $^{i i}$ & no & 1361 & 367 & 289.1 & 252.0 & 0.329 & 0.423 & 170 & $1 \cdot 10^{-5}$ \\
\hline
\end{tabular}

Note — $^{i}$ Leconte et al. (2013); ${ }^{i i}$ Wolf \& Toon (2015)

Table 2. Comparison of the climate at the present solar irradiance in ERA, Leconte et al. (2013), Wolf \& Toon (2015), and PlaSim data. The ozone $\left(\mathrm{O}_{3}\right)$ concentration, the total solar irradiance $(T S I)$, and the $\mathrm{CO}_{2}$ concentration are initial conditions. The surface temperature $\left(T_{S}\right)$, the effective temperature $\left(T_{e f f}\right)$, the Bond albedo $(\mathrm{A})$, and the normalized greenhouse parameter $\left(g_{n}\right)$ calculations are explained in Section 2. The temperature $\left(\mathrm{T}_{40}\right)$ and the water vapor mixing ratio $\left(q_{r}\right)$ are both measured at a pressure level of $40 \mathrm{hPa}$.

\begin{tabular}{c|cccc}
\hline \multicolumn{5}{c}{ Ice Melt } \\
\hline$\left[C O_{2}\right](\mathrm{ppm})$ & 560 & 388 & 280 & 200 \\
\hline$T_{S}^{c}(\mathrm{~K})^{i}$ & 303.1 & 303.0 & 303.0 & 303.1 \\
$\epsilon T_{S}^{c}(\mathrm{~K})$ & 0.3 & 0.3 & 0.4 & 0.1 \\
$S_{c}\left(S_{0}\right)$ & 1.0436 & 1.0524 & 1.0590 & 1.0703 \\
$\epsilon S_{c}\left(S_{0}\right)$ & $2 \times 10^{-4}$ & $2 \times 10^{-4}$ & $6 \times 10^{-4}$ & $1 \times 10^{-4}$ \\
\hline \multicolumn{5}{c}{ Moist Greenhouse Threshold } \\
\hline$\left.C O_{2}\right](\mathrm{ppm})$ & 560 & 388 & 280 & 200 \\
\hline$q_{r}^{d}(\mathrm{~g} / \mathrm{kg})^{i i}$ & 7.6 & 7.5 & 7.5 & 7.5 \\
$\epsilon q_{r}^{d}(\mathrm{~g} / \mathrm{kg})$ & 0.1 & 0.1 & 0.1 & 0.2 \\
$S_{d}\left(S_{0}\right)$ & 1.1485 & 1.1535 & 1.1586 & 1.1637 \\
$\epsilon S_{d}\left(S_{0}\right)$ & $4 \times 10^{-4}$ & $4 \times 10^{-4}$ & $3 \times 10^{-4}$ & $9 \times 10^{-4}$ \\
$T_{s t}(\mathrm{~K})$ & 242.6 & 242.5 & 242.8 & 242.9 \\
$\epsilon T_{s t}(\mathrm{~K})$ & 0.2 & 0.2 & 0.3 & 0.3 \\
$T_{S}^{d}(\mathrm{~K})$ & 320.0 & 320.0 & 320.1 & 320.1 \\
$\epsilon T_{S}^{d}(\mathrm{~K})$ & 0.2 & 0.2 & 0.2 & 0.2 \\
$S_{d}\left(\mathrm{~W} / \mathrm{m}^{2}\right)$ & 1563 & 1570 & 1577 & 1584 \\
$\mathrm{D}(\mathrm{AU})$ & 0.933 & 0.931 & 0.929 & 0.927 \\
\hline
\end{tabular}

Table 3. Polynomial Fittings. Inflection points of the surface temperature $\left(T_{S}\right)$ series and the water vapor mixing ratio $\left(q_{r}\right)$ series with respect to the solar irradiance $(\mathrm{S}$, in units of the solar constant $S_{0}$ ) for different $\mathrm{CO}_{2}$ concentrations. $\left(T_{S}^{c}, S_{c}\right)$ is the inflection point of the polynomial fitting of the surface temperature (Fig. 1). $\left(\mathrm{q}_{r}^{d}, S_{d}\right)$ is the inflection point of the polynomial fitting of the water mixing ratio (Fig. 4). $T_{S}^{d}$ and $T_{s t}$ are the surface temperature and the stratospheric temperature at the inflection point $S_{d}$. D is the equivalent orbital distance in astronomical units ( AU) for each case. Note. ${ }^{i} T_{S}(\mathrm{~S})=\sum_{i=0}^{3} \gamma_{i} S^{i}$

${ }^{i i} q_{r}(\mathrm{~S})=\sum_{j=0}^{3} \mu_{j} S^{j}$, where $\gamma_{i}$ and $\mu_{j}$ are the polynomial coefficients that depend on the $\mathrm{CO}_{2}$ concentration.

the logarithmic function

$$
S_{M G T}^{x}=\sigma_{1} \ln \left(\frac{\left[C O_{2}\right]^{x}}{\left[\mathrm{CO}_{2}\right]^{r}}\right)+\sigma_{2}
$$

\begin{tabular}{|c|c|c|c|c|}
\hline \multicolumn{5}{|c|}{ Moist Greenhouse Threshold } \\
\hline$\left[\mathrm{CO}_{2}\right](\mathrm{ppm})$ & 560 & 388 & 280 & 200 \\
\hline$S_{d}\left(S_{0}\right)^{i}$ & 1.1485 & 1.1535 & 1.1586 & 1.1637 \\
\hline$t_{d}(\mathrm{Gyr})^{i i}$ & 1.58 & 1.64 & 1.69 & 1.74 \\
\hline$\tau_{d}(\mathrm{Gyr})$ & 1.44 & 1.44 & 1.45 & 1.45 \\
\hline \multicolumn{5}{|c|}{ Opaque Atmosphere } \\
\hline$\left[\mathrm{CO}_{2}\right](\mathrm{ppm})$ & 560 & 388 & 280 & 200 \\
\hline$S_{e}\left(S_{0}\right)$ & 1.1897 & 1.1897 & 1.1897 & 1.1897 \\
\hline$t_{e}(\mathrm{Gyr})$ & 2.00 & 2.00 & 2.00 & 2.00 \\
\hline$\tau_{e}(\mathrm{Gyr})$ & 0.83 & 0.84 & 0.86 & 0.88 \\
\hline$\tau_{d, e}(\mathrm{Gyr})$ & 1.25 & 1.20 & 1.17 & 1.14 \\
\hline$\tau_{t}(\mathrm{Gyr})$ & 2.83 & 2.84 & 2.86 & 2.88 \\
\hline
\end{tabular}

Table 4. Water loss. $\left[\mathrm{CO}_{2}\right]$ is the $\mathrm{CO}_{2}$ concentration, $S$ is the solar irradiance, $t$ is the time to the future, $\tau_{d}$ is the water lifetime at the triggering of the moist greenhouse effect (state d) calculated following the conditions at that state, $\tau_{e}$ is the water lifetime at the state when the atmosphere becomes opaque (last point of the series), $\tau_{t}=t_{e}+\tau_{e}$ is the total time from the present to the complete loss of the planet's water, and $\tau_{d, e}=\tau_{t}-t_{d}$ is the total time from the moist greenhouse threshold to the complete loss of the planet's water.

Note. ${ }^{i} S(t)=-1.494+1.718 \cdot \mathrm{t}-0.469 \cdot \mathrm{t}^{2}+0.059 \cdot \mathrm{t}^{3}+(-0.003) \cdot \mathrm{t}^{4}$; ${ }^{i i} \epsilon \mathrm{t}=0.01$ Gyr.

where $S_{M G T}^{x}$ is the solar irradiance at the MGT for a given $\mathrm{CO}_{2}$ concentration, $\left[\mathrm{CO}_{2}\right]^{r}=280 \mathrm{ppm}$ is the preindustrial $\mathrm{CO}_{2}$ concentration, $\sigma_{1}=-1.486 \cdot 10^{-2} S_{0}$, and $\sigma_{2}=S_{M G T}^{r}=1.159 S_{0}$ (Table 3 and Fig. 8). This function allows us to calculate the MGT for different $\mathrm{CO}_{2}$ concentrations.

The equivalent orbital distance of the MGT in our present Solar System can be represented by the function

$$
D_{M G T}^{x}=\delta_{1} \ln \left(\frac{\left[\mathrm{CO}_{2}\right]^{x}}{\left[\mathrm{CO}_{2}\right]^{r}}\right)+\delta_{2}
$$

where $\delta_{1}=6.00 \cdot 10^{-3} \mathrm{AU}$ and $\delta_{2}=9.29 \cdot 10^{-1} \mathrm{AU}$. 


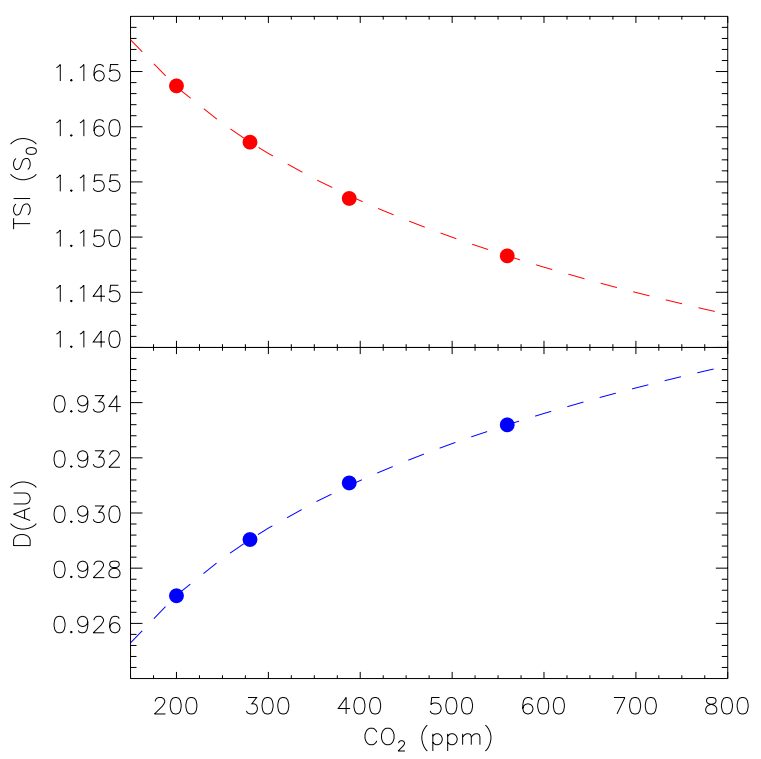

Figure 8. Total solar irradiance (TSI) at the moist greenhouse threshold and equivalent orbital distance in our present solar system as a function of the $\mathrm{CO}_{2}$ concentration. The TSI has been fitted as $S_{M G T}^{x}=\sigma_{1} \ln \left(\left[\mathrm{CO}_{2}\right]^{x} /\left[\mathrm{CO}_{2}\right]^{r}\right)+\sigma_{2}$, where $\sigma_{1}=-1.486 \cdot 10^{-2} S_{0}$ and $\sigma_{2}=1.159 S_{0}$ (red dash line) and the equivalent orbital distance as $D_{M G T}^{x}=$ $\delta_{1} \ln \left(\left[\mathrm{CO}_{2}\right]^{x} /\left[\mathrm{CO}_{2}\right]^{r}\right)+\delta_{2}$, where $\delta_{1}=6.00 \cdot 10^{-3} \mathrm{AU}$ and $\delta_{2}=9.29 \cdot 10^{-1} \mathrm{AU}$ (blue dashed line).

Using Eq. 19 to obtain $\mathrm{S}_{M G T}^{x}$ and $\mathrm{S}_{M G T}^{r}$ and supposing that the atmosphere is in equilibrium at TOA in each case $\left(S(1-A) / 4=\sigma T_{\text {eff }}^{4}\right)$, we can calculate the difference in the OLR $\left(O L R=\sigma T_{\text {eff }}^{4}\right)$ at the MGT between two Earth analog planets with different $\mathrm{CO}_{2}$ concentrations by

$$
\Delta\left(O L R_{M G T}\right)=\mu\left(5.35 \ln \frac{\left[\mathrm{CO}_{2}\right]^{x}}{\left[\mathrm{CO}_{2}\right]^{r}}\right)
$$

where $\Delta\left(O L R_{M G T}\right)$ is expressed in $\mathrm{W} \cdot \mathrm{m}^{-2}$ and $\mu=\sigma_{1} S_{0}\left(1-A_{M G T}^{x}\right) / 4=-0.72$. Note that the relation inside the parenthesis is Equation 1. However, Equation 21 does not represent a radiative forcing but the OLR difference at the MGT between two Earth analogs.

(e) The opaque atmosphere - The temperature of the planet and the water vapor concentration of the atmosphere continues to increase for larger values of the solar irradiance, and eventually, the opacity and the efficient emissivity $(\epsilon)$ of the atmosphere reach their maximum (Fig. 2). The sensible heat flux and the net LW radiation at the surface are reduced (Fig. 3), due to the intense humidity and the temperature inversion. Most of the energy absorbed by the surface is released in form of latent heat flux. The Simpson-Nakajima limit is reached when $\epsilon=1$. At this point, the OLR depends exclusively

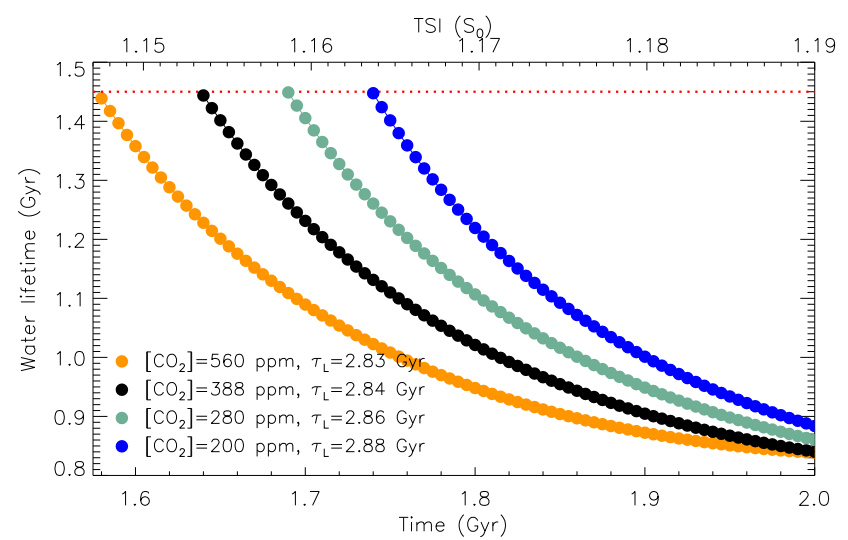

Figure 9. Water lifetime as a function of time and solar irradiance (top axis, in units of the solar constant $\mathrm{S}_{0}$ ) for four $\mathrm{CO}_{2}$ concentrations. The red dotted line corresponds to the moist greenhouse threshold (at this state, the water vapor mixing ratio is about $7.5 \mathrm{~g} \cdot \mathrm{kg}^{-1}$ and the surface temperature is $320 \mathrm{~K}$ for all the $\mathrm{CO}_{2}$ concentrations tested).

on the temperature of the top emitting layer. Our results place this limit at TSI 1.170 $\mathrm{S}_{0}$ for present-day $\mathrm{CO}_{2}$ concentration. This radiation value is equivalent to an orbital distance of $0.925 \mathrm{AU}$ in our present solar system. In contrast to recent studies (Goldblatt et al. 2013), we obtained an $\mathrm{OLR}_{\max } \sim 310 \mathrm{~W} \cdot \mathrm{m}^{-2}$ (Fig. 2), similar to Kasting (1988). We have not simulated larger solar forcings, because our model uses a broadband radiative transfer (see Section 2) that is not adapted to simulate such hot and humid states and clouds may form higher than $40 \mathrm{hPa}$, its top pressure level (Fig. 6).

\subsection{The water loss}

Figure 9 shows our results of the water lifetime of an Earth analog at each point from the MGT to the Simpson-Nakajima limit. The surface temperature of the planet continues to rise with the increase of solar luminosity with time, thus planetary habitability evolves. The water vapor mixing ratio and the escape rate change accordingly and the planet eventually enters into a runaway greenhouse state. We use the solar data given by Bahcall et al. (2001) to account for the evolution of the luminosity with time and we derive the corresponding water vapor mixing ratio value through the polynomial fitting of our model series.

In our simulations of an Earth analog (388 ppm of $\mathrm{CO}_{2}$ ), the MGT is reached at $1.154 \mathrm{~S}_{0}$. Bahcall et al. (2001) predicts an increase of the solar luminosity to $1.154 \mathrm{~S}_{0}$ in 1.64 billion years. Our results show that an Earth analogue at the moist greenhouse limit evolves to a Simpson-Nakajima limit, losing the ocean's water after 1.25 to 1.14 billion years, depending on the $\mathrm{CO}_{2}$ levels tested (Fig. 9 and Table 4). If the same planet is at the Simpson-Nakajima limit, it loses its water 


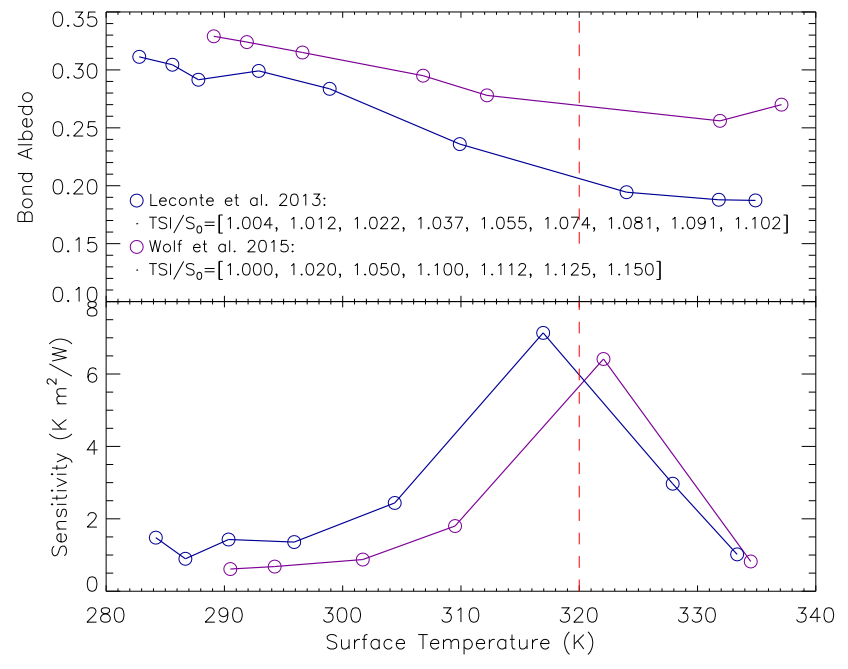

Figure 10. Bond albedo and climate sensitivity as a function of global mean surface temperature for the experiments in Leconte et al. (2013) $\left(\mathrm{CO}_{2}=376 \mathrm{ppm}\right)$ and in Wolf \& Toon (2015) $\left(\mathrm{CO}_{2}=367 \mathrm{ppm}\right)$. The solar irradiance at each point is given in units of the solar constant $\left(\mathrm{S}_{0}=1361.27 \mathrm{~W} \cdot \mathrm{m}^{-2}\right)$. The red dashed line indicates the surface temperature standard for the moist greenhouse threshold obtained in this article.

after 0.83 to 0.88 billion years, depending on the $\mathrm{CO}_{2}$ concentration. Thus, an Earth analog with the present $\mathrm{CO}_{2}$ concentration would enter in a moist greenhouse state and would gradually lose the full water content of the ocean within about 2.84 billion years.

\section{DISCUSSION}

\subsection{Comparison with previous GCM studies}

We compare our results with two previous GCM studies on the greenhouse effect of Earth-like planets. Leconte et al. (2013) (hereafter L13) simulates an Earthlike planet with an atmosphere composed by 1 bar of $\mathrm{N}_{2}, 376 \mathrm{ppm}$ of $\mathrm{CO}_{2}$, a variable amount of $\mathrm{H}_{2} \mathrm{O}$, and an initial $\mathrm{TSI}=1365 \mathrm{~W} \cdot \mathrm{m}^{-2}$ using a modified version of the LMD Generic GCM (LMDG); Wolf \& Toon (2015) (hereafter W15) uses a modified version of the Community Atmosphere Model (CAM4), with a similar composition of the atmosphere, $367 \mathrm{ppm}$ of $\mathrm{CO}_{2}$, and an initial TSI $=1361.27 \mathrm{~W} \cdot \mathrm{m}^{-2}$. Both models have a photochemical atmosphere, a correlated- $k$ radiative transfer scheme, implementing HITRAN 2008 and HITRAN $2004 k$-coefficients respectively, and include the water vapor continuum. They both use a mixed layer ocean scheme and a thermodynamic sea-ice model. The parameterization of the cumulus convection is different in each model: LMDG uses a moist convective adjustment scheme (Manabe et al. 1965; Forget et al. 1998), PlaSim uses a Kuo-type scheme (Kuo 1965, 1974), and CAM4 uses a mass-flux scheme (Zhang \& MacFarlane 1995). The last two schemes represent the penetrative cumulus convection and its interaction with the environment, which are important to simulate a proper distribution of the humidity and the clouds, while the convective adjustment does not include these effects. L13 accounts for the non-dilute regime of water by including a numerical scheme to calculate the atmospheric mass redistribution during condensation.

One of the main differences between this study and previous ones is that our simulations include atmospheric ozone. The structure of the atmosphere and the climate of Earth analogs without ozone differ substantially from that of our planet. For this reason, the climate simulations in L13 and W15 for the present solar irradiance differ with respect to ERA data (Table 2 and Fig. 5). Their tropopause levels at the present solar irradiance (about $3 \mathrm{hPa}$ in L13 and at $10 \mathrm{hPa}$ in $\mathrm{W} 15$ ) belong to the high stratosphere and the mesosphere in the present-day Earth. They obtain a lower stratospheric temperature $(170 \mathrm{~K}$ at $40 \mathrm{hPa})$, and a lower water mixing ratio at that level ( $\mathrm{q}_{r} \sim 10^{-5} \mathrm{~g} \cdot \mathrm{kg}^{-1}$ for both models). Additionally, W15 shows an albedo $12 \%$ higher and L13 obtains a surface temperature $6 \mathrm{~K}$ colder than our planet.

Although these previous GCM studies have similar initial conditions, they show large differences at the same solar irradiance (Table 2). For instance, L13 shows a surface temperature of about $285 \mathrm{~K}$ at the present solar irradiance, while in W15 is about $289 \mathrm{~K}$. The surface temperature is about $335 \mathrm{~K}$ at TSI $1.102 \mathrm{~S}_{0}$ in L13, while W15 shows a value of about $312 \mathrm{~K}$ at TSI 1.100 $\mathrm{S}_{0}$ (Fig. 10). Wolf \& Toon (2015) compared the climate sensitivity of both models, obtaining a peak between $\left[1.074 \mathrm{~S}_{0}\right.$, $\left.1.081 \mathrm{~S}_{0}\right]$ for L13 data, and a peak between $\left[1.112 \mathrm{~S}_{0}\right.$, $1.125 \mathrm{~S}_{0}$ ] for $\mathrm{W} 15$ data. These radiation values correspond to orbital distances about $0.96 \mathrm{AU}$ and $0.94 \mathrm{AU}$ in the present Solar System. Previous studies on the MGT measure $q_{r}$ at the lower stratosphere following the tropopause level, which increases with temperature (e.g Kasting 1988; Kasting et al. 1993; Kopparapu et al. 2013; Kasting et al. 2015). Following this, Wolf \& Toon (2015) reported a $q_{r} \sim 1.5 \cdot 10^{-2} \mathrm{~g} \cdot \mathrm{kg}^{-1}$ at the climate sensitivity peak, which differs with the value of $3 \mathrm{~g} \cdot \mathrm{kg}^{-1}$ obtained by Kasting et al. (1993). A water vapor mixing ratio $q_{r}>1 \mathrm{~g} \cdot \mathrm{kg}^{-1}$ is only reached at $1.19 \mathrm{~S}_{0}$ in W15.

In contrast with this studies, we compare the water vapor mixing ratio of each simulation at same pressure level $(40 \mathrm{hPa})$, since this level has been chosen as a compromise between the photodissociation and the concentration of water in the atmosphere. At the peak of climate sensitivity, the water mixing ratio value at $40 \mathrm{hPa}$ is between $[0.2,10] \mathrm{g} \cdot \mathrm{kg}^{-1}$ in L13 and between $[1,10] \mathrm{g} \cdot \mathrm{kg}^{-1}$ in W15. Both intervals are in agreement with $7.5 \mathrm{~g} \cdot \mathrm{kg}^{-1}$, the value obtained in our simulations. 
Our results are consistent with both ERA and W15 data (Fig. 5). Due to the effect of atmospheric ozone, our simulations of present-day Earth's climate obtain a better agreement with respect to ERA data than previous studies on Earth-like planets that do not include ozone. Despite the limitations of PlaSim, the variation of the mean global values with the surface temperature is similar to W15 data. We want to remark that the climate evolution of the atmosphere is not taken into account, since it requires a deeper understanding of the climate feedback and the capability to simulate them. Therefore, our results do not represent the climate evolution of a single planet, but the climate of Earth analogs with similar atmospheric composition and different solar irradiance.

\section{2. $M G T$}

An Earth analog planet with 388 ppm of $\mathrm{CO}_{2}$ reaches the MGT at TSI $\sim 1.154 \mathrm{~S}_{0}$, corresponding to an equivalent orbital distance of $0.931 \mathrm{AU}$ in the present solar system (Table 3). At larger concentrations of $\mathrm{CO}_{2}$, less stellar irradiance is needed to reach the MGT. Both $S_{M G T}$ and the $\Delta\left(O L R_{M G T}\right)$ (Equations 19 and Eq. 21, respectively) have a logarithmic dependence on the $\mathrm{CO}_{2}$ concentration, being consistent with Eq. 1. Note, however, that the values of the coefficients of the functions derived in this article might depend on the complexity of the model used.

Our simulations show that the global mean surface temperature at the MGT is $320 \mathrm{~K}$, independent of the $\mathrm{CO}_{2}$ concentrations tested. L13 and W15 did not run simulations near $320 \mathrm{~K}$, but despite the differences at the present Earth's state, their data show a climate sensitivity peak between $310 \mathrm{~K}$ and $330 \mathrm{~K}$ (Fig. 10), compatible with the MGT. Therefore, the temperature value proposed in this article is consistent with these two GCM studies.

\subsection{The water loss}

Our results of the water lifetime of an Earth analog differ from previous studies, because we identify the MGT by the inflection point of the water vapor mixing ratio series and we use the value of the water mixing ratio given by our model at this point $\left(\mathrm{q}_{r}=7.5 \mathrm{~g} \cdot \mathrm{kg}^{-1}\right)$, instead of using the earlier 1D model value $\left(\mathrm{q}_{r}=3 \mathrm{~g} \cdot \mathrm{kg}^{-1}\right.$, Kasting et al. 1993). In addition, we use solar data from a more recent solar model (Bahcall et al. 2001, instead of Gough 1981). As a consequence, the overall water lifetime on an Earth analog is reduced from 4.6 billion years (Kasting et al. 1993) (1D) and 3.50 billion years (Wolf \& Toon 2015) (3D) to 2.84 billion years (this paper).
These results do not take in account the evolution of the climate beyond the Simpson-Nakajima limit, which implies a further increase in temperature and a decrease of the water lifetime and they do not include other factors that may substantially modify them: for instance, it does not take in account the amount of water lost from the beginning of the moist greenhouse to the present conditions of the planet; changes in sea level and salinity, due to the melt of the polar ice caps and the moist greenhouse effect, will modify the evaporation rates and vary the temperature of the planet (Cullum and Stevens 2016); the recombination of water molecules decreases the hydrogen atoms reaching the top of the atmosphere; the modification of the ocean transport will have an impact on the climate (Knietzsch et al. 2015); the chemical evolution of the atmosphere; the variation of the solar UV radiation will change the photolysis rate of water (Claire et al. 2012), etc. These calculations are highly dependent on the value of the water mixing ratio. Therefore, the improvement of GCMs is essential to understand the role of the processes involved in the loss of Earth's water and to make estimates for other planets.

\section{CONCLUSIONS}

We use PlaSim, an intermediate complexity model, to perform a large number of GCM simulations in order to constrain the conditions of the MGT in Earth analogs. We include the radiative effect of ozone for the first time in GCM studies of Earth analogs. As a consequence, our representation of the current Earth's climate is in better agreement with ERA data than previous GCM studies of the moist greenhouse threshold that do not include ozone.

We explore the climate sensitivity to $\mathrm{CO}_{2}$. We identify three states where the planetary climate changes significantly: (i) the state of maximum cloud fraction, (ii) the complete melt of planet's ice and snow, and (iii) a large increase in the humidity of the stratosphere, corresponding to the MGT. In order to identify the increase in the stratospheric water vapor that characterizes the MGT for the first time in 3D simulations, we calculate the inflection point of the water vapor mixing ratio curve at $40 \mathrm{hPa}$. Since the evolution of both the stratosphere and the cold trap are not yet well understood, this pressure level represents a compromise between the dissociation and the concentration of water.

Our results show that, on an Earth-like planet with a $\mathrm{CO}_{2}$ concentration similar to the present level, the MGT is reached at a total solar irradiance of TSI $\sim 154 \mathrm{~S}_{0}$, corresponding to an equivalent orbital distance of $0.931 \mathrm{AU}$ in our solar system, which represents a new value for the inner edge of the Habitable Zone for Earth 
analogs with ozone, using an intermediate complexity GCM. The solar incoming radiation should increase to this value in about 1.64 billion years. In agreement with previous GCM studies, the troposphere is not completely saturated at this state in our simulations and there is a temperature increase in the low troposphere due to the water continuum absorption. Our results show that the irradiance at the MGT and the amount of atmospheric $\mathrm{CO}_{2}$ follow a logarithmic relation, consistent with the dependence of the $\mathrm{CO}_{2}$ radiative forcing with its concentration.

We update previous calculations of the water lifetime on an Earth analog planet by using the value of the water mixing ratio given by our model at the MGT $\left(q_{r} \sim 7.5 \mathrm{~g} \cdot \mathrm{kg}^{-1}\right)$, instead of using the value earlier obtained by $1 \mathrm{D}$ models $\left(q_{r} \sim 3 \mathrm{~g} \cdot \mathrm{kg}^{-1}\right)$. By using the value of the water mixing ratio given by our model and taking in account the radiative effect of ozone, we obtain a shorter water lifetime than previous studies, 2.84 billion years for an Earth analog, compared to 3.50 billion years (Wolf \& Toon 2015) and 4.6 billion years (Kasting et al.
1993).

In our simulations, the moist greenhouse effect is initiated by a large increase in the humidity of the stratosphere at a mean surface temperature $\mathrm{T}_{S} \sim 320 \mathrm{~K}$, independent of the $\mathrm{CO}_{2}$ concentration. Despite the modeling differences, this surface temperature value is consistent with previous GCM studies (Leconte et al. 2013; Wolf \& Toon 2015), suggesting that both the increase in the humidity of the stratosphere and a global mean surface temperature of $320 \mathrm{~K}$ might be robust indicators of the MGT in GCM simulations of Earth-like planets. These results should be further assessed using complex GCMs.

\section{ACKNOWLEDGEMENTS}

We thank Eric Wolf and Jérémy Leconte for making available CAM4 and LMDG data to us and for the valuable discussion. The authors acknowledge support by the Simons Foundation (SCOL 290357, Kaltenegger), the Carl Sagan Institute, and the Centre for the Mathematics of Planet Earth of the University of Reading.

\section{REFERENCES}

Abe, Y., Abe-Ouchi, A., Sleep, N. H., Zahnle, K. J. 2011.

Astrobiology 11, 443-460. doi:10.1089/ast.2010.0545

Arrhenius, S. 1896. The London, Edinburgh, and Dublin

Philosophical Magazine and Journal of Science, 41:251, 237-276. doi:10.1080/14786449608620846

Bahcall, J. N., Pinsonneault, M. H., Basu, S. 2001. ApJ555, 990-1012. doi:10.1086/321493

Berger, A. L. 1978a. Journal of Atmospheric Sciences 35, 2362-2367. doi:10.1175/1520-0469(1978)035¡2362:LTVODI¿22.0.CO;2

Berger, A. L. 1978b. Quaternary Research, 9, 2, 139 doi:10.1016/0033-5894(78)90064-9

Bindoff, N. L., Stott, P. A., Achuta Rao, K. M., Allen, M. R., Gillett, N., Gutzler, D., Hansingo, K., Hegerl, G., Hu, Y., Jain, S., Mokhov, I. I., Overland, J., Perlwitz, J., Sebbari, R., and Zhang, X. 2013. Climate Change 2013: The Physical Science Basis. Contribution of Working Group I to the Fifth Assessment Report of the Intergovernmental Panel on Climate Change. Cambridge University Press, Cambridge, United Kingdom and New York, NY, USA, 867. doi:10.1017/CBO9781107415324.022

Boer, G. J., McFarlane, N. A., Laprise, R., Henderson, J., and Blanchet, J.-P. 1984. Atmosphere-Ocean, 22, 397-429. doi:10.1080/07055900.1984.9649208

Bordi, I., Fraedrich, K., Sutera, A., Zhu, X. 2012.

Theoretical and Applied Climatology 109, 253-259. doi:10.1007/s00704-011-0579-5
Boschi, R., Lucarini, V., Pascale, S. 2013. Icarus226, 1724-1742. doi:10.1016/j.icarus.2013.03.017

Claire, M. W., Sheets, J., Cohen, M., Ribas, I., Meadows, V. S., Catling, D. C. 2012. ApJ757, 95. doi:10.1088/0004-637X/757/1/95

Collins, M., Knutti, R., Arblaster, J., Dufresne, J. L., Fichefet, T., Friedlingstein, P., Gao, X., Gutowski, W. J., Johns, T., Krinner, G., Shongwe, M., Tebaldi, C., Weaver, A. J., \& Wehner, M. 2013. Long-term climate change: projections, commitments and irreversibility. IPCC; Climate Change 2013: The Physical Science Basis. IPCC Working Group I Contribution to AR5. Cambridge University Press, Cambridge, UK and New York, USA, pp.1029-1136. doi:10.1017/CBO9781107415324.024

Cullum, J., Stevens, D. P. 2016. Proceedings of the National Academy of Science 113, 4278-4283.

doi:10.1073/pnas.1522034113

Eliasen, E., Machenhauer, B., \& Rasmussen, E. 1970. Rep. 2, Institut for Teoretisk Meteorologi, Kobenhavns Universitet, Denmark, $37 \mathrm{pp}$.

Etminan, M., Myhre, G., Highwood, E. J., Shine, K. P. 2016. Geophysical Research Letters 43, 12. doi:10.1002/2016GL071930

Evans, S. J., Toumi, R., Harries, J. E., Chipperfield, M. R., Russell, J. M. 1998. Journal of Geophysical Research 103, 8715-8725. doi:10.1029/98JD00265

Fioletov; V. E. 2008. Atmosphere-Ocean 46-1, 39-67.doi:10.3137/ao.460103 
Forget, F., Hourdin, F., \& Talagrand, O. 1998. Icarus131, 302. doi:10.1006/icar.1997.5874

Forster, P., Ramaswamy, V., Artaxo, P., Berntsen, T., Betts, R., Fahey, D. W., Haywood, J., Lean, J., Lowe, D. C., Myhre, G., Nganga, J., Prinn, R., Raga, G., Schulz M., and Van Dorland, R. 2007. Changes in Atmospheric Constituents and in Radiative Forcing. In: Climate Change 2007: The Physical Science Basis. Contribution of Working Group I to the Fourth Assessment Report of the Intergovernmental Panel on Climate Change [Solomon, S., Qin, D., Manning, M., Chen, Z., Marquis, M., Averyt, K. B.,Tignor M., and Miller H.L. (eds.)]. (Cambridge University Press, Cambridge, United Kingdom and New York, NY, USA). http://www.ipcc.ch/publications_ and_data/ar4/wg1/en/ch2.html

Forster, P. 2016. Annual Review of Earth and Planetary Sciences. 44, 85-106. doi:10.1146/annurev-earth-060614-105156.

Fraedrich, K., Jansen, H., Kirk, E., Luksch, U., Lunkeit, F. 2005. Meteorologische Zeitschrift 14, 299-304. doi:10.1127/0941-2948/2005/0043

Fraedrich, K., Jansen, H., Kirk, E., Lunkeit, F. 2005. Meteorologische Zeitschrift 14, 305-314. doi:10.1127/0941-2948/2005/0044

Fraedrich, K., Lunkeit, F. 2008. Tellus Series A 60, 921-931. doi:10.1111/j.1600-0870.2008.00338.x

Garcia, R. R., Solomon, S. 1983. Journal of Geophysical Research 88, 1379-1400. doi:10.1029/JC088iC02p01379

Goldblatt, C., Robinson, T. D., Zahnle, K. J., Crisp, D. 2013. Nature Geophysics6, 661-667. doi:10.1038/ngeo1892

Gough, D. O. 1981. Solar Physics 74, 21-34. doi:10.1007/BF00151270

Green, A. E. S. 1964. Applied Optics, 3, 203-208. doi:10.1364/AO.3.000203

Hartmann, D. L., Klein Tank, A. M. G., Rusticucci, M., Alexander, L. V., Brnnimann, S., Charabi, Y., Dentener, F. J., Dlugokencky, E. J., Easterling, D. R., Kaplan, A., Soden, B. J., Thorne, P. W., Wild M., and Zhai, P. M. 2013. Observations: Atmosphere and Surface. In: Climate Change 2013: The Physical Science Basis. Contribution of Working Group I to the Fifth Assessment Report of the Intergovernmental Panel on Climate Change [Stocker, T. F., D. Qin, G.-K. Plattner, M. Tignor, S. K. Allen, J. Boschung, A. Nauels, Y. Xia, V. Bex and P.M. Midgley (eds.)]. Cambridge University Press, Cambridge, United Kingdom and New York, NY, USA, pp. 159254, doi:10.1017/CBO9781107415324.008

Hersbach, H., Peubey, C., Simmons, A., Berrisford, P., Poli, P., Dee, D. 2015. Quarterly Journal of the Royal Meteorological Society 141, 2350-2375. doi:10.1002/qj.2528
Hunten, D. M. 1973. Journal of Atmospheric Sciences 30, 1481-1494. doi:10.1175/1520-0469(1973)030¡1481:TEOLGF ¿2.0.CO;2

Kasting, J. F. 1988. Icarus74, 472-494. doi:10.1016/0019-1035(88)90116-9

Kasting, J. F., Chen, H., Kopparapu, R. K. 2015. ApJ813, L3. doi:10.1088/2041-8205/813/1/L3

Kasting, J. F., Pollack, J. B., Ackerman, T. P. 1984. Icarus57, 335-355. doi:g/10.1016/0019-1035(84)90122-2

Kasting, J. F., Whitmire, D. P., Reynolds, R. T. 1993. Icarus101, 108-128. doi:/10.1006/icar.1993.1010

Katayama, A. 1972. Department of Meteorology, Tech. Rep. No. 6, Dept. of Meteor., U.C.L.A., 77 p.

Kilic, C., Raible, C. C., Stocker, T. F. 2017. ApJ844, 147. doi:10.3847/1538-4357/aa7a03

Knietzsch, M.-A., Schroder, A., Lucarini, V., Lunkeit, F. 2015. Earth System Dynamics 6, 591-615. doi:10.5194/esd-6-591-2015

Kopparapu, R. K., Ramirez, R., Kasting, J. F., Eymet, V., Robinson, T. D., Mahadevan, S., Terrien, R. C., Domagal-Goldman, S., Meadows, V., Deshpande, R. 2013. ApJ765, 131. doi:10.1088/0004-637X/765/2/131

Kuo, H. L. 1965. Journal of Atmospheric Sciences 22, 40-63. doi:10.1175/1520-0469(1965)022;0040:OFAIOT¿2.0.CO;2

Kuo, H. L. 1974. Journal of Atmospheric Sciences, 31, 1232. doi:10.1175/1520-0469(1974)031¡1232:FSOTPO ¿2.0.CO;2

Lacis, A. A., Hansen, J. 1974. Journal of Atmospheric Sciences 31, 118-133. doi:/10.1175/15200469(1974)031;0118:APFTAO ¿2.0.CO;2

Laursen, L., Eliasen, E. 1989. Tellus Series A 41, 385-400. doi:/10.3402/tellusa.v41i5.11848

Leconte, J., Forget, F., Charnay, B., Wordsworth, R., \& Pottier, A. 2013. Nature, 504, 268. doi:10.1038/nature12827

Linsenmeier, M., Pascale, S., Lucarini, V. 2015. Planetary and Space Science 105, 43-59. doi:10.1016/j.pss.2014.11.003

London, J. 1980. Proceedings of the NATO Advanced Study Institute on Atmospheric Ozone. 1980. Nicolet, M., and Aikin, A. C. (Ed.), Washington, DC: US Department of Transportation, 1980., 31.

Louis, J.-F. 1979. Boundary-Layer Meteorology 17, 187-202. doi:10.1007/BF00117978

Lucarini, V., Fraedrich, K., Lunkeit, F. 2010a. Quarterly Journal of the Royal Meteorological Society 136, 2-11. doi:https://doi.org/10.1002/qj.543

Lucarini, V., Fraedrich, K., Lunkeit, F. Atmos. Chem. \& Phys. Discussions 10, 3699-3715 (2010b). doi:10.5194/acp-10-9729-2010

Lucarini, V., Ragone, F. 2011. Reviews of Geophysics 49, RG1001. doi:10.1029/2009RG000323 
Lucarini, V., Pascale, S., Boschi, R., Kirk, E., Iro, N. 2013. Astronomische Nachrichten 334, 576. doi:10.1002/asna.201311903

Lunkeit, F., Fraedrich, K., Jansen, H., Kirk, E., Kleidon, A., and Luksch, U. 2011. Planet Simulator, Reference Manual. Technical Report, University of Hamburg.

https://www.mi . uni-hamburg.de/en/arbeitsgruppen/

theoretische-meteorologie/modelle/sources/

psusersguide.pdf

Manabe, S. and Möller, F. M. 1961. Mon Wea. Rev., 89, 503-532. doi:10.1175/15200493(1961)089¡0503:OTREAH ¿2.0.CO;2

Manabe, S., Smagorinsky, J., \& Strickler, R. F. 1965. Monthly Weather Review, 93, 769. doi:10.1175/1520-0493(1965)093¡0769:SCOAGC¿2.3.CO;2

Manabe, S., Wetherald, R. T. 1975. Journal of Atmospheric Sciences 32, 3-15. doi:10.1175/15200469(1975)032;0003:TEODTC ¿2.0.CO;2

Myhre, G., Highwood, E. J., Shine, K. P., Stordal, F. 1998. Geophysical Research Letters 25, 2715-2718. doi:10.1029/98GL01908

Myhre, G., D. Shindell, Bréon, F. M., Collins, W., Fuglestvedt, J., Huang, J., Koch, D., Lamarque, J. F., Lee, D., Mendoza, B., Nakajima, T., Robock, A., Stephens, G., Takemura, T., \& Zhang, H. 2013. Anthropogenic and Natural Radiative Forcing. In: Climate Change 2013: The Physical Science Basis. Contribution of Working Group I to the Fifth Assessment Report of the Intergovernmental Panel on Climate Change [Stocker, T.F., D. Qin, G.-K. Plattner, M. Tignor, S.K. Allen, J. Boschung, A. Nauels, Y. Xia, V. Bex and P.M. Midgley (eds.)]. Cambridge University Press, Cambridge, United Kingdom and New York, NY, USA. doi:10.1017/CBO9781107415324.018

Nakajima, S., Hayashi, Y.-Y., Abe, Y. 1992. Journal of Atmospheric Sciences 49, 2256-2266. doi:10.1175/1520-0469(1992)049¡2256:ASOTGE ¿2.0.CO;2

Orszag, S. A. 1970. Journal of the Atmospheric Sciences, 27: 6, 890-895. doi:10.1175/15200469(1970)027¡0890:TMFTCO ¿2.0.CO;2

Pascale, S., Gregory, J. M., Ambaum, M., Tailleux, R. 2011. Climate Dynamics 36, 1189-1206. doi:10.1007/s00382-009-0718-1

Poli, P., Hersbach, H., Tan, D. G. H., Dee, D., P., Thpaut, J-J., Simmons, A. J., Peubey, C., Komori, T., Vitart, F., Laloyaux, P., Berrisford, P., Dragari., R., Trmolet, Y., Hlm, E. V., Bonavita, M., Isaksen, L., Fisher, M. 2013. ECMWF, Shinfield Park, Reading. ERA Report Series 14, 59.
Poli, P., Hersbach, H., Dee, D. P., Berrisford, P., Simmons, A. J., Vitart, F., Laloyaux, P., Tan, D. G. H., Peubey, C., Thpaut, J-J., Trmolet, Y., Hlm, E. V., Bonavita, M., Isaksen, L., Fisher, M. 2016. Journal of Climate 29, 4083-4097. doi:10.1175/JCLI-D-15-0556.1. https: //www.ecmwf .int/en/elibrary/

11699-data-assimilation-system-and-initial-performance-eval

Popp, M., Schmidt, H., Marotzke, J. 2016. Nature

Communications 7, 10627. doi:10.1038/ncomms10627

Ragone, F., Lucarini, V., Lunkeit, F. 2016. Climate Dynamics 46, 1459-1471 (2016). doi:10.1007/s00382-015-2657-3

Ramirez, R. M., Kaltenegger, L. 2014. ApJ797, L25. doi:10.1088/2041-8205/797/2/L25

Ramirez, R. M., Kaltenegger, L. 2016. ApJ823, 6. doi:10.3847/0004-637X/823/1/6

Roeckner, E., Arpe, K., Rockel, B., Bengtsson, L., Duemenil, L., Esch, M., Kirk, E., Lunkeit, F., Schubert, S., Windelband, M., Schlese, U., Brinkop, S., Ponater, M., Sausen, R. 1992. Max-Planck-Institut fr Meteorologie, Hamburg. Technical report 93.

https://www.mpimet.mpg.de/fileadmin/ publikationen/Reports/MPI-Report_93.pdf

Rodgers, C. D., 1967. Q. J. R. Meteorol. Soc., 93, 43-54.

Sasamori, T. 1968. Journal of Applied Meteorology 7, 721-729. doi:10.1175/1520-0450(1968)007;0721:TRCCFA ¿2.0.CO;2

Schröder, K.-P., Connon Smith, R. 2008. Monthly Notices of the Royal Astronomical Society 386, 155-163. doi:10.1111/j.1365-2966.2008.13022.x

Simpson, G. C. 1927. Quarterly Journal of the Royal Meteorological Society 53, 213-232. doi:10.1002/qj.49705322303

Slingo, A., Slingo, J. M. 1991. Journal of Geophysical Research 96, 15 doi:10.1029/91JD00930

Stephens, G. L. 1978. Journal of Atmospheric Sciences 35, 2123-2132. doi:10.1175/1520-0469(1978)035¡2123:RPIEWC¿2.0.CO;2

Stephens, G. L., Ackerman, S., Smith, E. A. 1984. Journal of Atmospheric Sciences 41, 687-690. doi:10.1175/1520-0469(1984)041;0687:ASPRTI ¿2.0.CO;2

Tian, W., Chipperfield, M. P., Lü, D. 2009. Advances in Atmospheric Sciences 26, 423-437. doi:10.1007/s00376-009-0423-3

Tiedtke, M. 1988. Schlesinger M.E. (eds) Physically-Based Modeling and Simulation of Climate and Climatic Change. NATO ASI Series (Series C: Mathematical and Physical Sciences), Springer, Dordrecht. Ch. 9, vol 243, 375-431. https ://www . springer . com/la/book/9789027727886

Towe, K. M. 1981. Precambrian Research, 16, 1. doi:10.1016/0301-9268(81)90002-4 
Trenberth, K. E., Fasullo, J. T., \& Kiehl, J. 2009. Bulletin of the American Meteorological Society, 90, 311. doi:10.1029/201609GL037527

Wolf, E. T., \& Toon, O. B. 2015. Journal of Geophysical Research (Atmospheres), 120, 5775.

doi:10.1002/2015JD023302
Wordsworth, R. D., Pierrehumbert, R. T. 2013. ApJ778, 154. doi:10.1088/0004-637X/778/2/154

Yang, J., Boué, G., Fabrycky, D. C., Abbot, D. S. 2014.ApJ787, L2. doi:10.1088/2041-8205/787/1/L2

Zhang, G. J., \& McFarlane N. A. 1995. Atmosphere-Ocean Vol. 33 , Iss. 3, 407. doi:10.1080/07055900.1995.9649539 